\title{
Electricity Distribution Networks: Investment and Regulation, and Uncertain Demand
}

Tooraj Jamasb and Cristiano Marantes

January 2011

CWPE 1115 \& EPRG 1104 


\title{
Electricity Distribution Networks: Investment and Regulation, and Uncertain Demand
}

\author{
EPRG Working Paper 1104
}

Cambridge Working Paper in Economics 1115

\section{Tooraj Jamasb and Cristiano Marantes}

\begin{abstract}
Electricity distribution networks are capital intensive systems and timely investments are crucial for long-term reliability of their service. In coming years, in the UK, and elsewhere in Europe, many networks are in need of extensive investments in their aging assets. Also, aspects of energy policy concerning climate change, renewable energy, energy efficiency, demand side management (DSM), network energy loss reduction, quality of service standards, and security of supply require active, flexible, and smart networks that can be achieved through investments. This paper is a chapter in the forthcoming book "Jamasb T. and Pollitt, M. G. (2011) Eds., The Future of Electricity Demand: Customers, Citizens and Loads, Cambridge University Press: Cambridge" and describes a network investment assessment model developed as a tool to identify and assess the investment requirements of distribution networks. A broadening of the scope of network investments to include demand-related measures can reduce the need for investments.
\end{abstract}

Keywords

JEL Classification
Contact

Publication

Financial Support t.jamasb@hw.ac.uk

January 2011

EDF Networks
$\mathrm{E} \cdot \mathrm{S} \cdot \mathrm{R} \cdot \mathrm{C}$ ECONOMIC \& SOCIA RESEARCH COUNCIL 


\title{
Electricity Distribution Networks:
}

\section{Investment and Regulation, and Uncertain Demand ${ }^{1}$}

\author{
Tooraj Jamasb ${ }^{2}$ \\ Department of Economics, Heriot-Watt University
}

Cristiano Marantes

UK Power Networks ${ }^{3}$

\footnotetext{
${ }^{1}$ This paper is a version of a chapter in the forthcoming book "Jamasb, T. and Pollitt, M. G., Eds. (2011). The Future of Electricity Demand: Customers, Citizens and Loads, Cambridge University Press". The work was supported by ESRC Electricity Research Group and the EPSRC Flexnet project. The authors would like to acknowledge support from UK Power Networks.

${ }^{2}$ Corresponding author. Heriot-Watt University, Department of Economics, Mary Burton Building, EH14 4AS Edinburgh, United Kingdom, Phone: +44-(0)131 458 3482, Email: t.jamasb@hw.ac.uk

${ }^{3}$ Formerly EDF Energy Networks.
} 


\section{Introduction}

Electricity distribution networks are highly capital intensive systems and timely investments to maintain and upgrade the assets are crucial for long-term reliability and expansion of their service. In coming years, in the UK, and elsewhere in Europe, many distribution networks are in need of extensive investments in their aging assets. At the same time, aspects of energy policy concerning climate change, renewable energy sources, energy efficiency, demand side management (DSM), network energy loss reduction, quality of service standards, and even security of supply (Jamasb and Pollitt, 2008) require active, flexible, and smart networks that can be achieved through significant investments.

At the same time, the utilities' investment decisions are dependent on the regulatory framework within which they operate. Following the liberalisation of the electricity sectors around the world, the introduction of incentive regulation regimes based on RPI-X models and benchmarking has in most cases improved the efficiency of network utilities. Cost savings can be achieved either in operation and maintenance (Opex) and capital expenditures (Capex). Evaluation of efficiency potential in Capex is a challenging task. The main difficulty in incentivising investments is in the discrepancy between the long economic life and the cyclical nature of network assets on the one hand and the considerably shorter (five years in the UK) distribution price control periods on the other. Here both better planning and implementation of investments or a mere reduction in investments can both appear as achieving efficiency improvement in the short and medium-term while the implications of under-investment can become apparent in the long run.

Most of the efficiency improvements in the UK Distribution Network Operators (DNOs) have been in the form of savings in Opex which have been subject to stricter regulatory benchmarking and incentives. However, capital investments are not an integrated part of the cost benchmarking exercise and individual utility investment plans need to be approved by the regulator. The regulator has developed incentive 
schemes resembling a menu of options to encourage efficiency in capital investments based on engineering consultants' assessments. Nevertheless, assessing the effectiveness of investment efficiency incentives remains a difficult task due to the long time-horizons involved in network investments, information asymmetry between the regulator and the utility, and the five-year focus of distribution price control reviews.

The investments needs of the different regions of a network can vary greatly mainly due to differences in asset age and load growth. At the same time, the investment needs of meeting some of the above mentioned requirements from active and flexible networks can have mainly localised effects on the networks. For example, increase in distributed or micro generation in parts of the network or interest in power generation activities by councils and communities can lead to such local network effects. Therefore, there is a need for models that can be used to assess and regulate investments at sub-network level.

This chapter describes and utilises the use of a network investment assessment model developed as a practical tool to identify and assess the investment requirements of a particular group of distribution networks in the UK. A broadening of the scope of network investments to include demand-related measures such as micro-generation, distributed generation, and energy efficiency is likely to achieve overall investment reductions. However, the regulatory framework also needs adapt in accordance with the changing role of the future networks and in order to harness the benefit of a wider range of investment possibilities.

The next section provides the main features of the current UK distribution network regulation. Section 3 discusses regulation of active networks and demand. Section 4 discusses demand for distribution network services and drivers for capital investments. Section 5 describes a network model developed by EDF Energy for assessing local investment needs of networks which is used in our analysis. Section 6 offers some discussion of future distribution regulation frameworks and conclusions. 


\section{Distribution Networks and their Operating Environment}

\subsection{Background}

This section describes the role of electricity distribution networks and their operating environment emphasizing the importance of capital investments in the networks and the role of regulation for achieving the appropriate type and level of investments in the networks. The features of the UK incentive regulation and benchmarking regime are described in detail elsewhere in the literature (see, e.g., Pollitt, 2005; Jamasb and Pollitt, 2007).

The electricity system consists of generation, transmission, distribution and supply activities. Generation comprises production and conversion of electric power. Transmission involves long distance transportation of electricity at high voltage. Distribution is transportation of low voltage electricity through local networks from the transmission network to customers' premises. The supply function consists of metering, billing, and sale of electricity to end-users. The generation and supply activities are generally regarded as potentially competitive. The transmission and distribution networks are characterised as natural monopolies and are hence subject to economic regulation.

Distribution networks consist of overhead lines, cables, switchgear, transformers, control systems and meters to transfer electricity making them capital intensive activities. Much of these assets have long economic lives and become sunk costs upon investment. Also, distribution networks have a diverse set of residential, commercial, and industrial customers in terms usage level as well as consumption patterns. As demand for electricity service continues to increase the existing networks need to gradually be replaced and expanded and the utilities can experience investment cycles.

Due to their strategic position in the electricity system - as the main physical interface to end-users as well as to distributed generation (DG) sources, micro-generation units, smart meters, and the transmission network - distribution networks will have a central 
role to play in enabling an active demand side and a future low carbon electricity system. Living up to this expectation requires that these utilities undertake substantial investments in new technologies and solutions that transform them to active, flexible, and smart networks.

As electricity distribution is a capital intensive activity the efficiency with which the required investments are undertaken is a concern for the regulator. The main aim of electricity reform in general and incentive regulation of networks in particular is to provide utilities with incentives to improve their operating and investment efficiency and at the same time to ensure that consumers benefit from the gains. However, despite progress in economic regulation of networks in recent years, devising suitable incentives for network investments still remains a work in progress and a challenge for the regulators (see Joskow, 2008, Ofgem 2010).

\subsection{The Regulatory Framework}

As a result of the reform, there have been significant changes in the way that DNOs structure their business and the range of activities in which they are involved. For example, in the UK, several DNOs have active second-tier supply businesses and most are active in the supply of gas as well as electricity. This provides opportunities for joint marketing of the two fuels. Meanwhile some DNOs are now in different ownership from their former supply businesses. Following a series of mergers, the distribution businesses of the 14 original regional electricity companies (RECs) are currently (late 2010) owned by 7 independent companies.

The regulation model of distribution networks in Britain consists of a hybrid of incentive schemes. Under the current arrangements, the operating expenditures, capital expenditures, quality of service, and network energy losses are incentivised separately and under different types of schemes within a building block framework. The utilities' controllable operating expenditures (Opex) are incentivised by 
benchmarking these against an efficient frontier that is made up of the best practice DNOs in the sector. The allowed Opex of individual DNOs is set such that it requires them to close a specific proportion of their performance gap relative to the frontier during the price control period. In addition, the DNOs are given a general technical efficiency improvement target that is common to all DNOs (Pollitt, 2005; Jamasb and Pollitt, 2007).

In response to regulators incentives and benchmarking, operating expenditures of DNOs have fallen significantly while new investments are added to a growing regulatory asset base. As a result, capital investments are increasingly driving the regulated revenue of the DNOs.

\subsection{The Price Control Process}

The process for assessing the required level of capital expenditure over a price control review period is as follows. Utilities must draft business plans which include projected capital expenditure. These are then audited by a firm of engineering consultants, working for Ofgem. Usually these consultants recommend lower levels of capital expenditure than that proposed by each utility. This gives a base level of required capital expenditure to which an incentive scheme is applied. The incentive scheme resembles a menu of contracts regulation model. The menu of contracts approach is appealing at the presence of strong information asymmetry. However, this approach is

not widely used in practice with the main difficulty being development of a set of suitable menu of options (Pollitt, 2005).

In addition, quality of service and network energy losses are incentivised separately through performance standards and targets. The targets for each DNO are individual and deviation from these results in company specific penalties and rewards calculated based on an elaborate system. The rewards and penalties directly affect the total allowed revenue. In order to avoid jeopardizing financial viability of the companies, the 
maximum amount subject to quality of service reward and penalty scheme is capped as a percentage of allowed revenue. The 2004 distribution price control (for the period 2005-10) review introduced a sliding scale system to incentives capital investments by which the DNOs are rewarded by higher rate of returns if their actual investments are lower than the predicted levels (Ofgem, 2004). Collectively, these separate incentive schemes for Opex, Capex, quality of service, and network energy losses amount to a revenue cap incentive regulation.

Due to the presence of potential trade-offs between Opex, Capex, quality of service, and network losses, from an economic efficiency point of view, it is preferable to use an integrated regulation and perhaps even a benchmarking model. Such a model would be based on a single total expenditure measure where all cost measures as well as some measure of monetary values of service quality and network losses are added together. The hybrid system in Britain is contrary to the notion of integrated overall incentive regulation. However, the adopted approach - segmented regulation - gives more control to the regulator to address specific and urgent areas of focus. It also involves less complicated modelling than a fully integrated benchmarking model would require and is more transparent and easier to implement. At the same time, the current incentive system cannot account for the potential trade-off between the specific regulated aspects of the utilities.

The investment efficiency incentive scheme adopted by Ofgem as part of distribution price control reviews offers some flexibility for the utilities to perform better than their allowed and expected investment needs. This approach also, to some extent, enables the utilities, when possible, to take the trade-offs with operating expenditures into consideration. For the most recent distribution price control period (2010-15) there has been an equalization of the incentive rate for Opex and Capex reductions, which should reduce the incentives to inefficiently substitute capital expenditure for operating expenditure (see Ofgem, 2009). 


\section{Regulation of Active Network and Demand}

Ofgem's benchmarking model of DNOs can be described as a short-term efficiency model as it only addresses the companies' operating expenditures. This is in contrast to the long lead times necessary for the firms to change their asset structure. Capital expenditures are controlled and incentivised under a separate scheme.

Achieving long-term efficiency improvements can require short-term increases in Capex and/or Opex expenditures that may not generate immediate efficiency improvements. Indeed, such expenditure increases by a given firm can weaken its short-term performance relative to other firms. This can prevent firms from embarking on types of investments that have long-term efficiency gains. Such efficiency improvements can be facilitated with incentives allowing the firms to keep a larger share of the benefits of the efficiency gains. This is particularly the case with investment programmes in active networks and demand which are capital intensive and investment projects can have long lead times than can exceed the current fiveyear price control reviews.

The mismatch between the long-term horizon of investments and short price control periods can also have a negative effect on the cost of financing investments (see Ofwat/Ofgem, 2006). Longer regulatory periods (e.g. seven or ten years) can reduce uncertainty with regards to long-term investments and retaining their benefits. However, even substantially longer regulatory price control periods will likely not fully incentivise investments if the innovations appear to have even longer payback periods.

The current regulatory framework will need to evolve in order to enable the transition of the networks from passive system components to active and flexible actors. For example, Niesten (2010) discusses some aspects of regulation that can help encourage the required investments in distribution networks to connect distributed generation (DG). Among others, for example, the study argues that DG can pay a capacity-based network connection charges and be paid for the amount of energy that they supply to distribution networks. 
Saplacan (2008) describes how the perception of the activities of the DNOs has evolved and distinguishes between network ownership and network operation, the former being natural monopoly while the latter can potentially be open to 'competition for markets'. The study outlines a detailed breakdown of the different types of activities of distribution networks some of which can potentially be subject to competition. In the coming years, due to technological progress the dividing lines between regulation and the market can be redrawn so that more functions can be subjected to competition. Such a trend may result in a larger role for the use of market-based solutions for some aspects of active networks and demand.

Ofgem has been conducting a review of its price control processes. This has already led to proposals for a move towards 'Sustainable Network Regulation', which will seek to put strengthen incentives for network companies to facilitate low carbon investments on their networks (e.g. of local distributed generation from renewable resources). This will be based on a wider definition of network outputs than in the past where regulated revenue will be based on incentives, innovation and outputs (so called RIIO regulation) (see Ofgem, 2010).

\section{Demand for Distribution Services and Drivers of Investment}

\subsection{Background}

There is an extensive body of literature on electricity demand modeling and forecasts. Steinbuks (this volume) presents a review of the recent literature and references on this topic. However, the literature on electricity demand is predominantly focused on generation, capacity and, occasionally, related investments. The investment requirements of distribution networks are generally assumed to be a rough function of demand growth and typically at the macro-level and only a small subset of studies are concerned with demand for distribution network services and related investments. 
Also, in the past utilities have mainly used simple demand forecast methods and technical analysis to predict and plan their investment requirements.

In this paper we assess the drivers of demand for distribution network services and investments. Demand for electric energy and related services are initiated by endusers. Generators provide the required electricity in real time which is then delivered through the high voltage transmission and medium-low voltage distribution networks. The need for services of distribution networks can therefore be characterized as a 'derived demand' where network investment requirements are driven by end-users demand for electricity.

The distribution networks provide the final physical link to the electricity system allowing grid connected electricity generation to be delivered to end-users at the required location, quantity, and time. The need for load-related investments of distribution utilities are linked to demand for electricity. It is useful to distinguish between the two main types of investments in distribution networks.

i. Asset replacement and upgrading - These investments are aimed at maintaining the services of the network to existing customers. Asset renewal needs arise from aging assets that need to be renewed. In addition, demand growth from existing customers can lead to replacement and upgrading of certain asset types such as transformers. Asset registers and probability-based methods can be used to determine their optimum renewal time. The technical useful life of typical main network assets is long and their economic life may sometimes extend beyond their technical life.

ii. Network expansion - the size and shape of distribution networks evolve gradually in response to the changes in the demand and customer base. Over time, some customers or sites may be disconnected and/or leave the network while new customers and sites are constantly connected to the network. Demand for new connections in existing or parts of the service area lead to investment in expansion of the system. 
The relative share of investments in asset replacement and new investments can vary among utilities, for example, depending on the age profile of assets and network reinforcement and expansion requirements in their service areas.

A question that arises is the extent to which macroeconomic type of variables can be used to forecast uncertain demand for network investment at the level of utilities' service areas. Indeed this is a difficult task. In particular, the degree of difficulty increases for smaller service areas as the high-level or macro-economic type relations between the main factors become less reliable. An appealing approach is to use correlation analysis to identify accurate drivers for demand. However, the available data and previous studies are not sufficient for detailed service area analysis where indivisibilities of network capacity and demand at individual nodes in the distribution network may be large. For example, the length of the time-series used in correlations is too short to draw firm conclusions. Moreover, some correlations of potential driving factors of demand and investment among the service areas as, for example, used in CEPA (2009) and Frontier Economics (2007) reveal considerable regional differences which cannot be readily explained without further detailed studies.

In particular, investment planning under economic uncertainty is difficult. Much of the historical data that can be used in forecasts are from periods of relatively stable economic and demand growth. The energy demand and the economy relationship under economic down-turn (at least in the short/medium-term) may be very different from those of past trends. However, the nature of this relationship at times of economic downturn is not well understood. For example, the effect of economic activity on demand for electricity can be asymmetric - i.e. the negative effect of GDP reduction on demand for energy is not simply the inverse of a positive effect of GDP growth as shown in Mork (1989) or the case of oil prices.

In short, past trends are unlikely to provide good indicators for planning future network investment in particular for short-term applications to economic environment such as those of the late 2000s with negative economic growth. For example, flexible 
work arrangements adopted some sectors of the economy may mark a change in trend labour-energy-economy relationships.

\subsection{Drivers of Load-Related Investments}

In this study we assess the load growth and associated investment requirements for two main customer groups - i.e. 'residential' and 'non-residential sectors'. ${ }^{4}$ A number of indicators can be considered as drivers of residential and non-residential demand and investment. Error! Reference source not found. shows some investment drivers that can be used at utility level. These drivers differ in terms of the directness of their effect on demand and the tangibility of their relationship to actual investments in network assets. In addition, a recurring issue with many of the commonly used variables in energy forecasting models is that there is often strong degree of correlation among them making the identification of accurate demand and investment drivers more difficult.

The choice between the above mentioned demand and investment drivers can depend on the level of analysis. In the absence of extensive data and inconclusive evidence on specific drivers for utility-level investments we need to turn to economic reasoning and engineering experience in order to select key indicators of demand and investment.

\section{Model Description}

This section describes a comprehensive long term maximum electricity demand forecast methodology developed by EDF Energy Networks, UK. It produces highly disaggregated outputs as it attributes unique demand growth values to every single

\footnotetext{
${ }^{4}$ By non-residential demand we mean commercial and industrial demand.
} 
primary substation depending on their geographical location. Electricity demand is assumed to have a domestic and non-domestic component. This methodology is based on publicly available information and is therefore applicable to all DNOs in the UK.

In the UK, all DNOs have an obligation under their distribution license to plan and develop the distribution networks in accordance with a standard not below that set out in the Engineering Recommendation P2/6 of the Energy Networks Association. This prescribes the level of redundancy in the distribution network needed for various magnitudes of demand and specifies the speed with which service to customers should be restored when these fail. Moreover, maintaining future P2/6 compliance influences the longer-term investment in distribution networks by indicating when reinforcement is necessary.

A key factor when carrying out a reinforcement assessment is the prediction of future network demand. Knowing the existing demand on a substation, the underlying growth rate and any future demand increases due to specific known developments, allows an estimate to be made as to when a substation capacity will be insufficient to support demand in the future. With this knowledge, strategies can be developed to achieve optimal timing of network reinforcement.

Although network reinforcement is driven mainly by demand growth, other factors such as energy efficiency and integration of distributed generation have the potential to defer some demand related network reinforcement. However, the networks should be provided with appropriate incentives to consider active network and demand type of investments alongside conventional network development investments. Developing a robust investment assessment tool based on demand forecast methodology is of paramount importance for DNOs to meet their long-term license conditions as economically and efficiently as possible. 


\subsection{Forecasting domestic electricity demand}

It is common practice within the electricity industry to calculate domestic electricity demand based on the combination of the annual average electricity unit consumption ( $\mathrm{kWh} /$ year) and the maximum demand profile of a set of consumers. Studies of detailed demand data have indicated that daily demand profiles of consumers of the same type have a similar shape and also that the demand of a group of consumers is closely related to the annual electricity consumption of those consumers. This is the basis of a statistical analysis approach termed Demand Estimation Based on Units and Time (DEBUT) $)^{5}$, which uses the above information to calculate the average maximum demand of a group of consumers while recognising that the maximum demand of individual consumers may not occur at the same time. This measure of maximum average individual demand is called After Diversity Maximum Demand (ADMD), specified in $\mathrm{kW}$, which is commonly used by distribution network planners to design new distribution networks.

One of the benefits of basing ADMD calculation on annual average electricity unit consumption is that it takes into account demand-influencing factors such as the size of dwellings and the availability of gas supply. This is depicted in Figure 1, which shows the annual average electricity unit consumption ( $\mathrm{kWh} / \mathrm{year}$ ) for all Local Authority Districts (Boroughs in London) within EDF Energy Networks licensed areas. This information is published by the Department of Energy and Climate Change (DEEC) on an annual basis. ${ }^{6}$

\footnotetext{
${ }^{5}$ Engineering Technical Report 115 (1988).

${ }^{6}$ DECC Sub-national energy consumption statistics (http://www.decc.gov.uk/en/content/cms/statistics/).
} 
As it can be seen, average electricity consumption can range from 3600 to 5900 $\mathrm{kWh} /$ year and therefore using a single notional average would misrepresent regional consumption variations. For example, the average electricity consumption per dwelling in Islington is substantially less than in Mid Suffolk, as average properties in Islington would be smaller and proprieties in Mid-Suffolk would have limited access to gas networks.

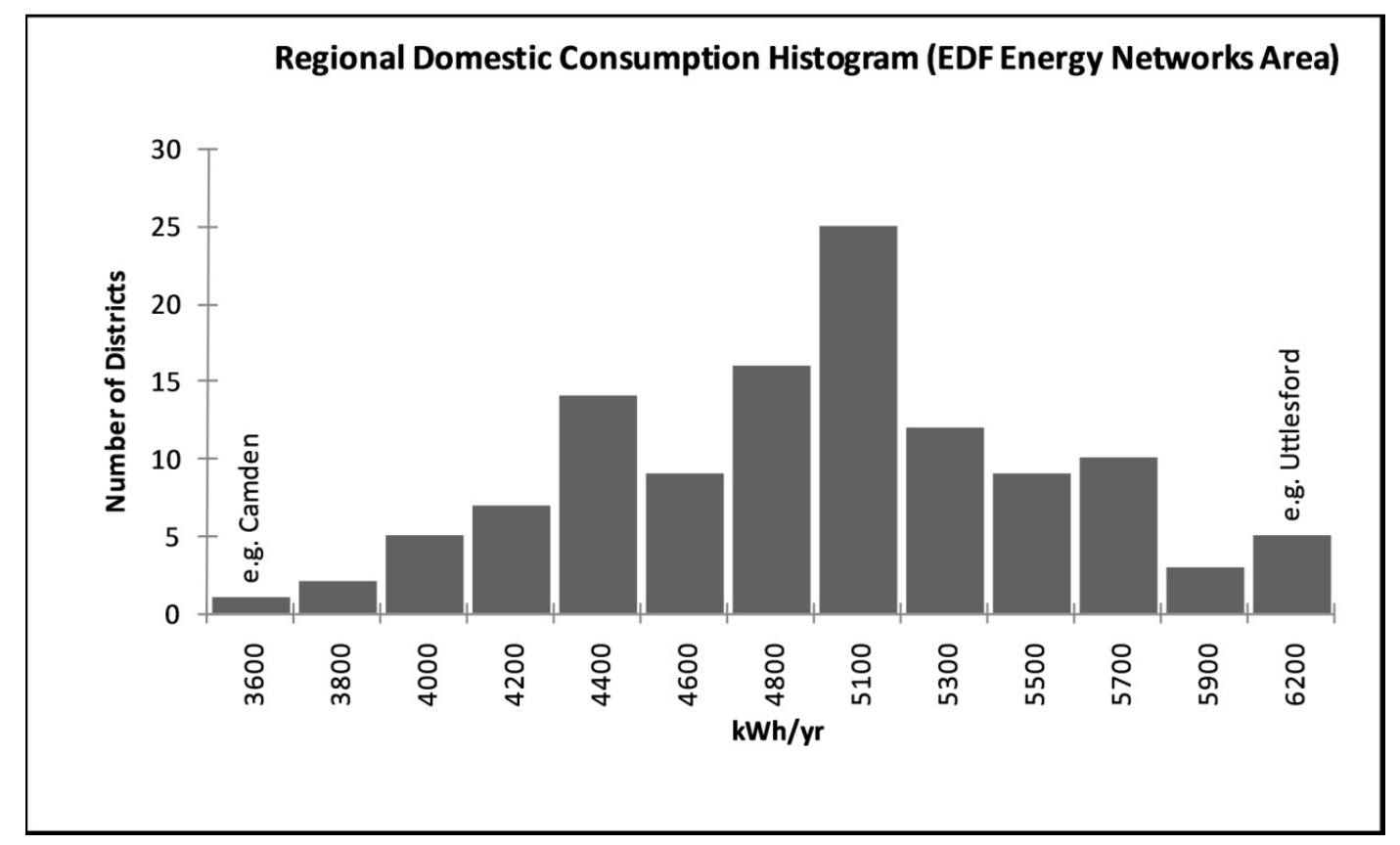

Figure 1: Average annual domestic electricity consumption per meter point (kWh)

A crucial step in estimating the average domestic electricity demand going forward involves forecasting the growth in the number of electricity customers or the number of electricity meters since each electricity consumer has a meter, referred to as MPAN (Metering Point Administration Number). However, forecasting the number of MPANs directly is not always practicable and therefore alternative variables are required as a proxy to MPANs growth. On a theoretical level, dwellings, household and MPANs are strongly related variables, (see Table 1 ). 
Table 1: Measures of residential electricity demand

\begin{tabular}{cl}
\hline Household & $\begin{array}{l}\text { One person or group of people living at the same address who share a } \\
\text { living area or at least one meal per day. }\end{array}$ \\
\hline Dwelling & $\begin{array}{l}\text { A self-contained accommodation unit that contains all of its rooms and } \\
\text { essential facilities - e.g. a shared dwelling could be made up of } \\
\text { households that share a kitchen (but not a living area, otherwise they } \\
\text { would be only one household). }\end{array}$ \\
MPAN & $\begin{array}{l}\text { Metering Point Administration Number - a unique number given to } \\
\text { every electricity customer. }\end{array}$
\end{tabular}

However, a study commissioned for EDF Energy Networks shows that the growth of households appears to overestimate the growth in MPANs, most notably in London. On the other hand growth in the number of MPANs appears to follow growth in the number of dwellings (

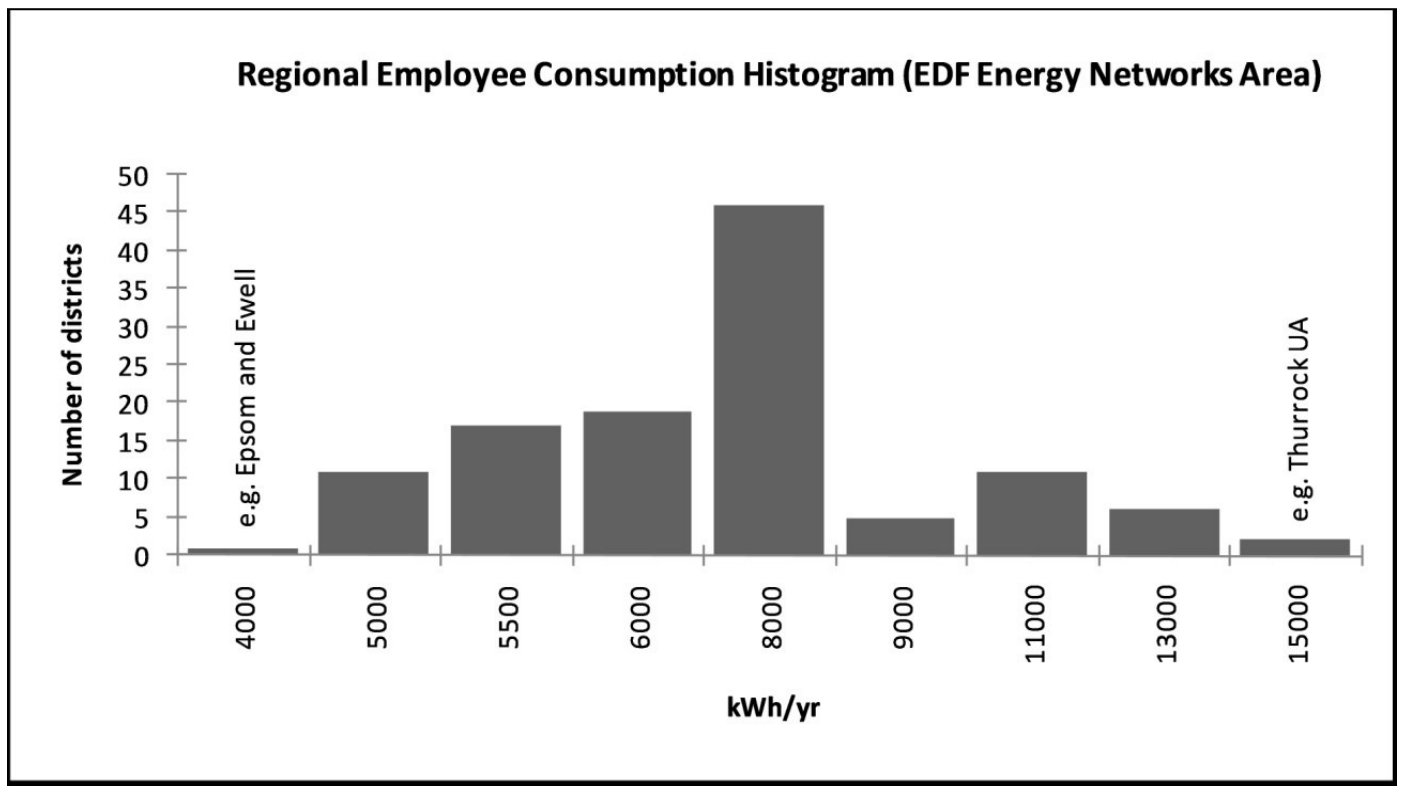

Figure 2). 


\section{Regional Employee Consumption Histogram (EDF Energy Networks Area)}

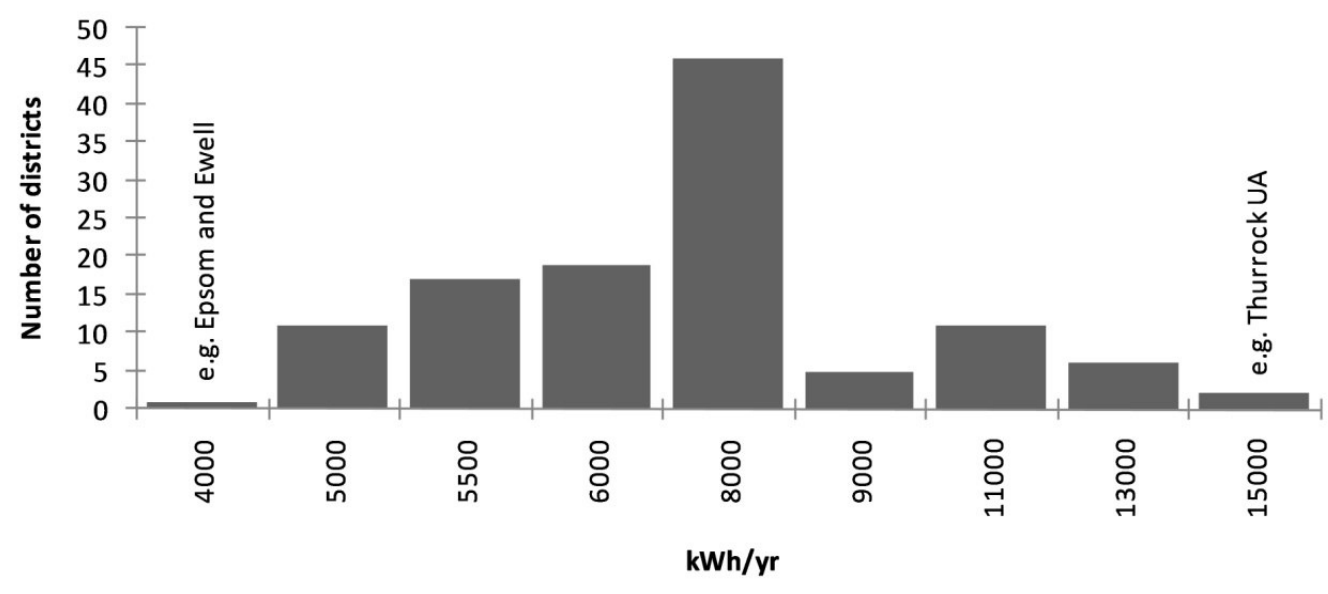

Figure 2: Comparison of measures of residential demand in three EDF Energy Networks service areas: LPN, SPN and EPN

Although the above analysis is based on the relatively short period of time for which EDF Energy Networks MPAN data is available, the one-to-one relationship between dwellings and MPANs seems reasonable as, in broad terms, new dwellings are expected to have their own electricity meter (MPAN) and hence represents a single new connection.

In the UK, long term dwelling provision targets are set by the Government and this information is publicly available at Local Authority District level (Boroughs in London) ${ }^{7}$. Therefore, using this information together with the ADMD figures described previously allows the expected long-term domestic demand to be derived at a Local Authority District level (Boroughs in London) as described in

Equation 1:

\footnotetext{
7 Regional Spatial Strategy Plans such as "East of England Plan" (www.eera.gov.uk), "South East of England Plan" (www.southeast-ra.gov.uk) and "The London Plan"(www.london.gov.uk/thelondonplan).
} 


\section{Equation 1}

Domestic demand $(\mathrm{kW})=[$ Number of dwelling $] \times[$ ADMD/dwelling $]$

\subsection{Forecasting non-domestic electricity demand}

Production theory in economics generally regards energy, labour, and capital as the main input factors in production processes. Within this framework, energy and labour can be viewed as complementary inputs. However, a change in the relative prices of labour and energy can, in the long-run, lead to substitution of the relatively more expensive factor with the cheaper one (see Platchkov and Pollitt, this volume, for a longer run perspective on this). Theory also suggests that in the short-run the stock of capital is fixed while the use of labour can be more flexible. Hence an energy price shock in the short-term can result in some reduced use of labour. In the long-run the stock of capital becomes more flexible and some factor substitution in response to changes in relative prices can take place.

Gross Value Added (GVA) is a measure of economic activity that in principle encompasses all energy use in production processes whether these are substitutes for or complimentary with the amount of labour input. A workplace-based measure of GVA (that allocates the income of commuters to the region in which they work) can be a good indicator of the industrial and commercial activity within the service area of a given DNO. However, local GVA is currently not available. Moreover, although GVA has interesting theoretical properties the suitability of it for the purpose of the present model is uncertain and needs to be examined carefully in future versions of the model. The main concern is the extent to which the theoretical relationships between labour, energy, and GVA or production still hold at disaggregated and fairly small geographic areas as required by the model.

Hence in this chapter the described methodology uses the number of jobs as a proxy for non-domestic demand growth as detailed projections of appropriate detailed level are publicly available. A practical advantage of using labour as a driver of non- 
residential demand is that it is more easily observable and measurable in physical terms and hence is more easily translatable to specific investments in load related network assets where past engineering knowledge and experience can also aid the investment decisions.

The electricity consumption statistics in the form of kWh/employee for all Local Authority Districts in the UK, are published by the Department of Energy Climate Change (DECC) on an annual basis ${ }^{8}$. At it can be seen in

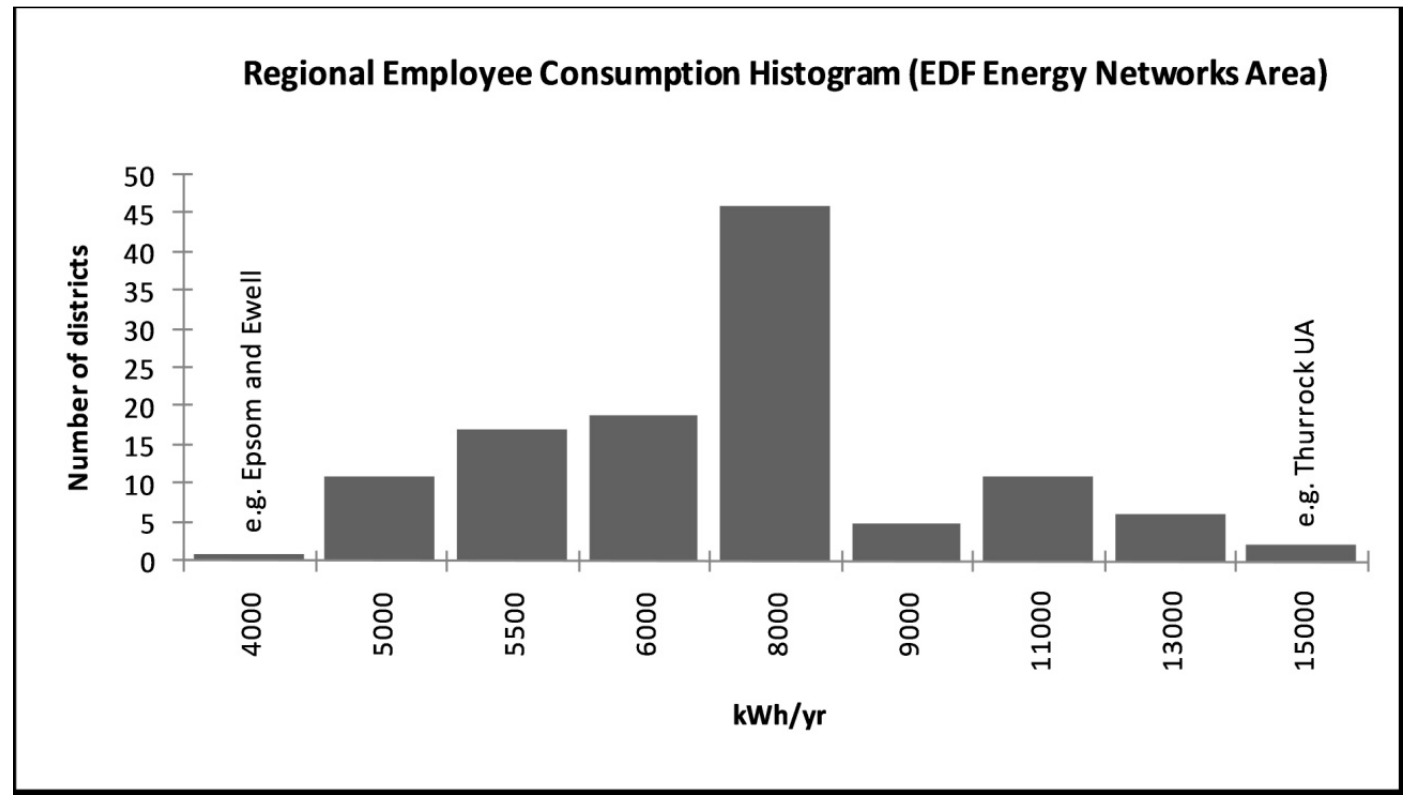

Figure 3, the average annual electricity consumption per employee varies significantly amongst the Local Authority Districts within EDF Energy Networks area of operation. The figure illustrates the diversity of non-domestic activity, which must be taken into account whilst forecasting non-domestic demand.

\footnotetext{
${ }^{8}$ DECC Sub-national energy consumption statistics (http://www.decc.gov.uk/en/content/cms/statistics/).
} 


\section{Regional Employee Consumption Histogram (EDF Energy Networks Area)}

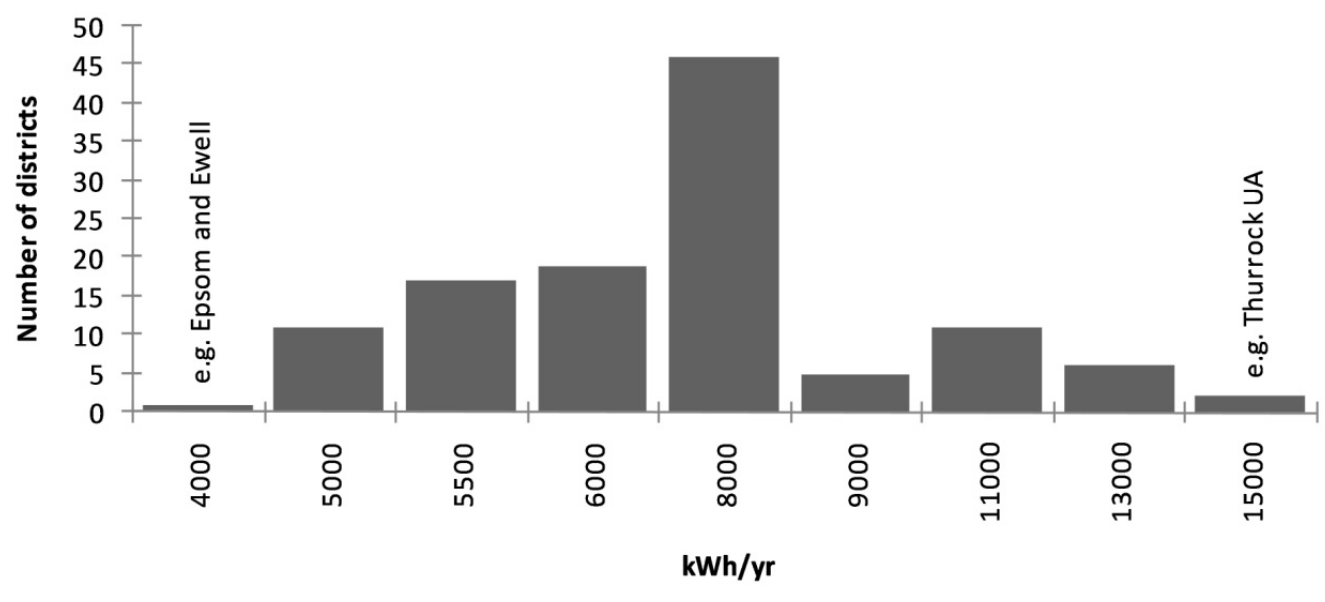

Figure 3: Average annual industrial and commercial electricity consumption per employee $(k W h)$

Source: Oxera analysis

In order to translate the above information into demand ( $\mathrm{kW} / \mathrm{employee),} \mathrm{as} \mathrm{opposed}$ to energy ( $\mathrm{kWh} / \mathrm{employee),} \mathrm{the} \mathrm{current} \mathrm{methodology} \mathrm{assumes} \mathrm{a} \mathrm{notional} \mathrm{load} \mathrm{factor,}$ which takes a view of the average usage profiles of employees. The baseline figure assumes a usage profile of eight hours/day, six days/week, 50 weeks/year, which is equivalent to $2400 \mathrm{~h}$ a year. ${ }^{9}$ The latter together with regional electricity consumption per employee (

\footnotetext{
${ }^{9}$ The assumptions reflect the fact that some industrial and commercial users work for 6 or 7 days/week - i.e. more than the average 5 days/week.
} 


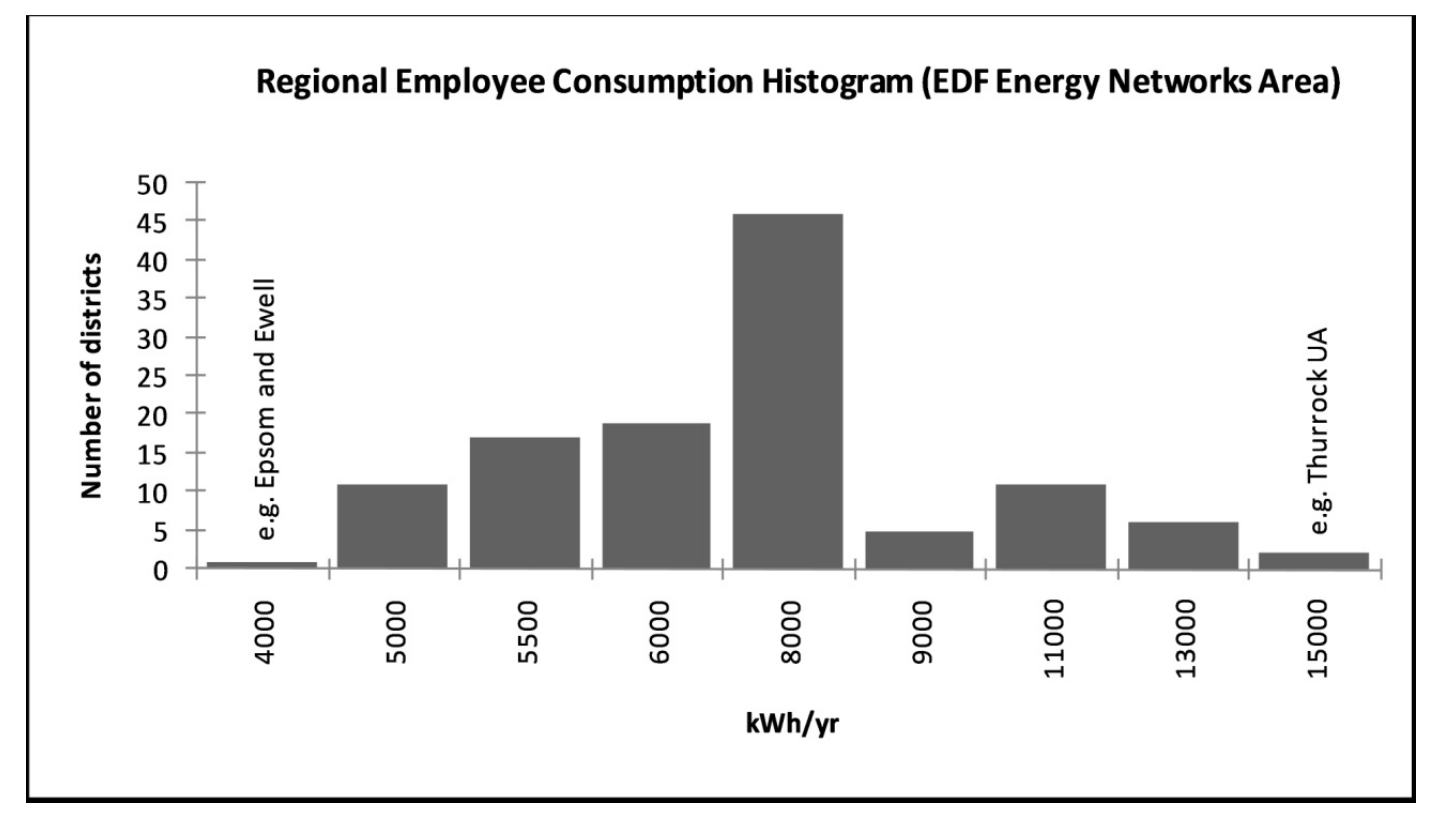

Figure 3) produces a regional demand per employee (kW/employee) as in

Equation 2.

\section{Equation 2}

$\mathrm{kW} /$ employee $=\mathrm{kWh} / \mathrm{employee} \div$ usage profile

The regional annual employment targets for all Local Authority Districts are currently published by the UK Government. This information provides a strong indication of the level of non-domestic activity, which can then be converted into electricity demand. This is achieved by multiplying regional employment targets by the regional demand per employee as in

Equation 3:

\section{Equation 3}


Regional non-domestic demand $(\mathrm{kW})=$ [regional annual employment targets $\mathrm{X}$ [regional demand per employee (kW/employee)]

\subsection{Regional electricity demand growth}

The above sections describe the main factors that have an impact on domestic and non-domestic demand growth. A strength of the methodology described here is that it is based on publicly available information published by the Department of Energy and Climate Change, Regional Development Agencies and other UK Government institutions. Moreover, it allows all UK DNOs to take into account UK Government housing and employment targets and convert this information into electricity demand growth.

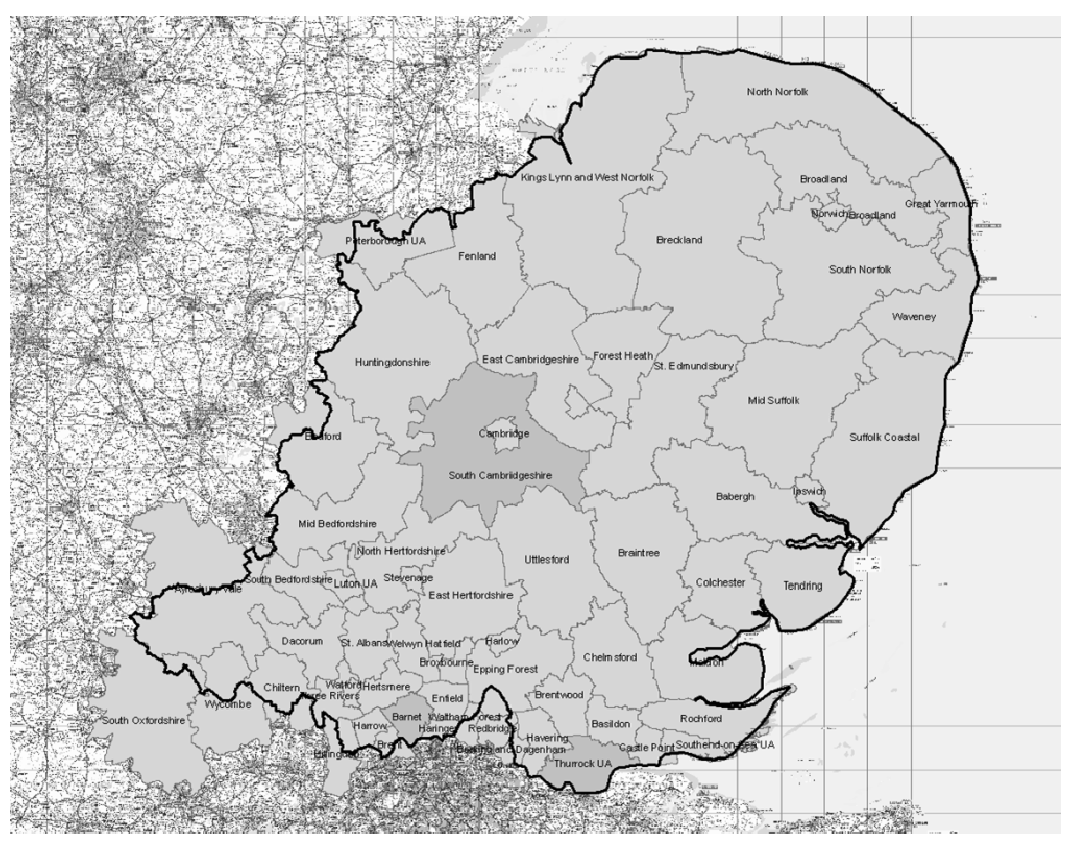

Year 2010 


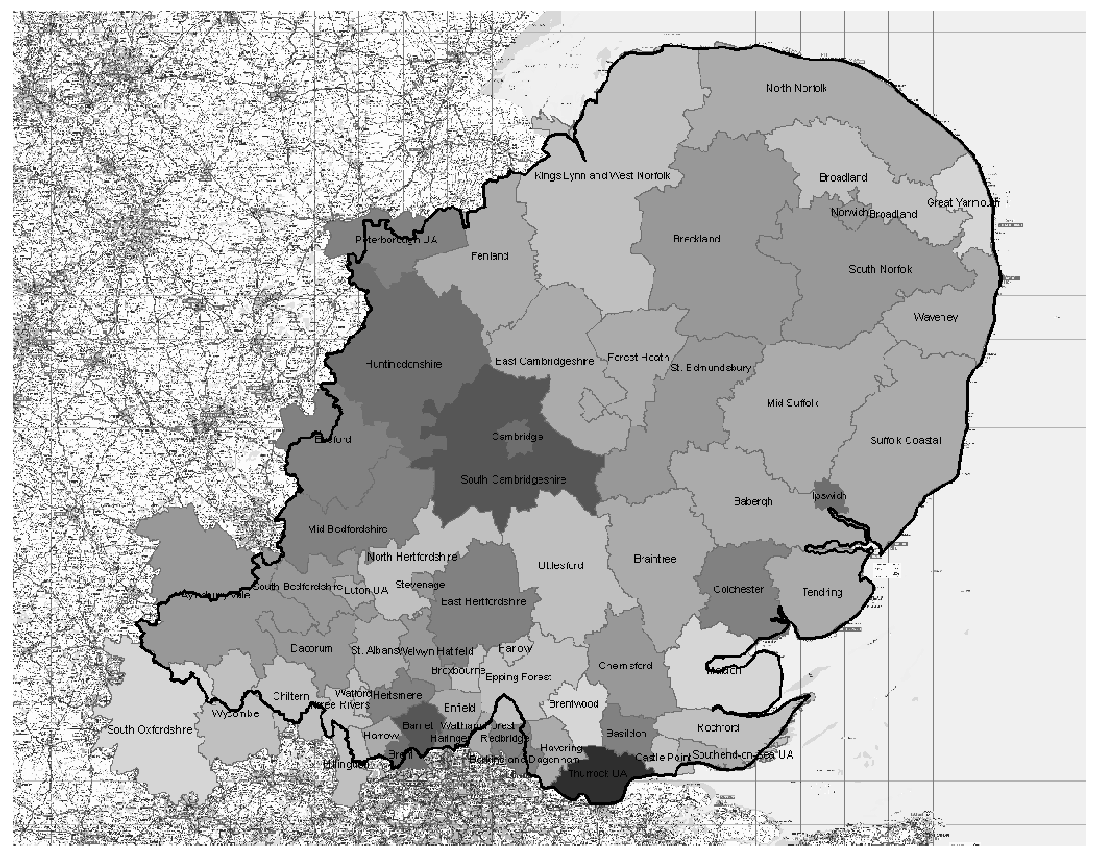

Year 2015

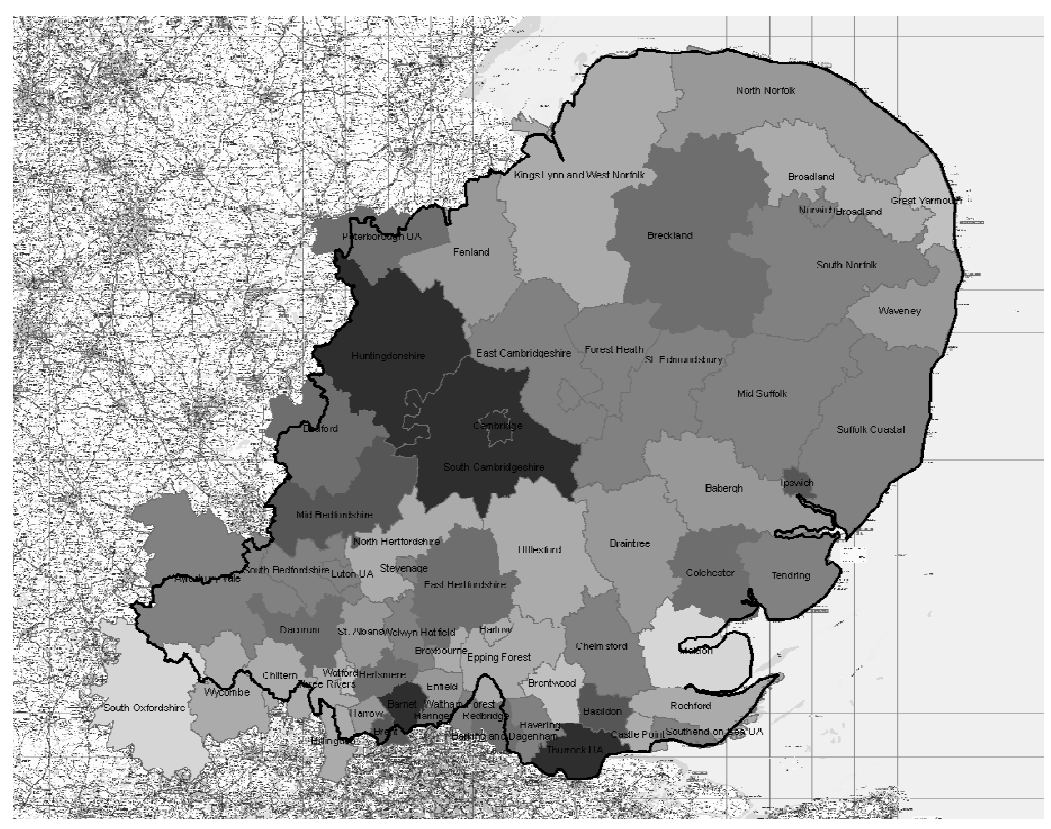

Year 2020

Figure 4 illustrates the outcome of this regional electricity demand growth methodology. It depicts the regional demand growth for one of EDF Energy Networks 
licensed areas, $\mathrm{EPN},{ }^{10}$ up to 2020 . Housing and employment long-term targets were obtained directly from the East of England Plan. ${ }^{11}$

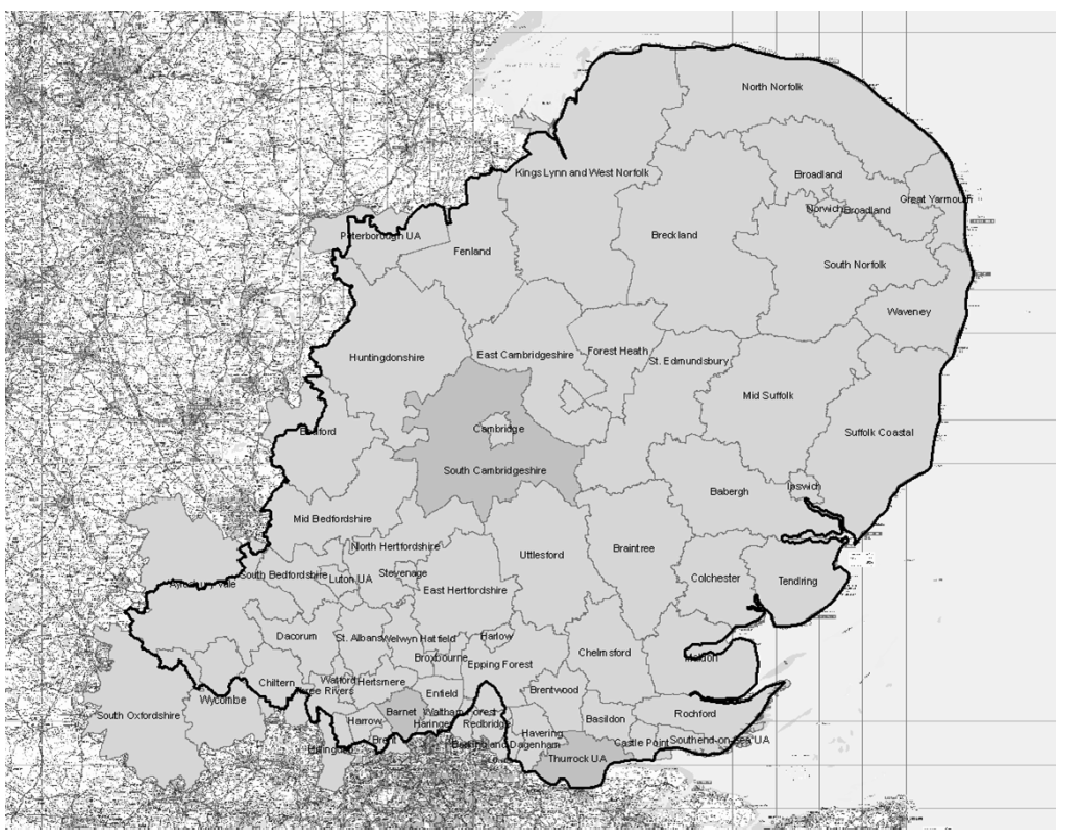

Year 2010

\footnotetext{
${ }^{10}$ Available at http://www.edfenergy.com/products-services/networks, last accessed 31 August 2010.

${ }^{11}$ East of England Plan (available at www.eera.gov.uk, last accessed 31 August 2010).
} 


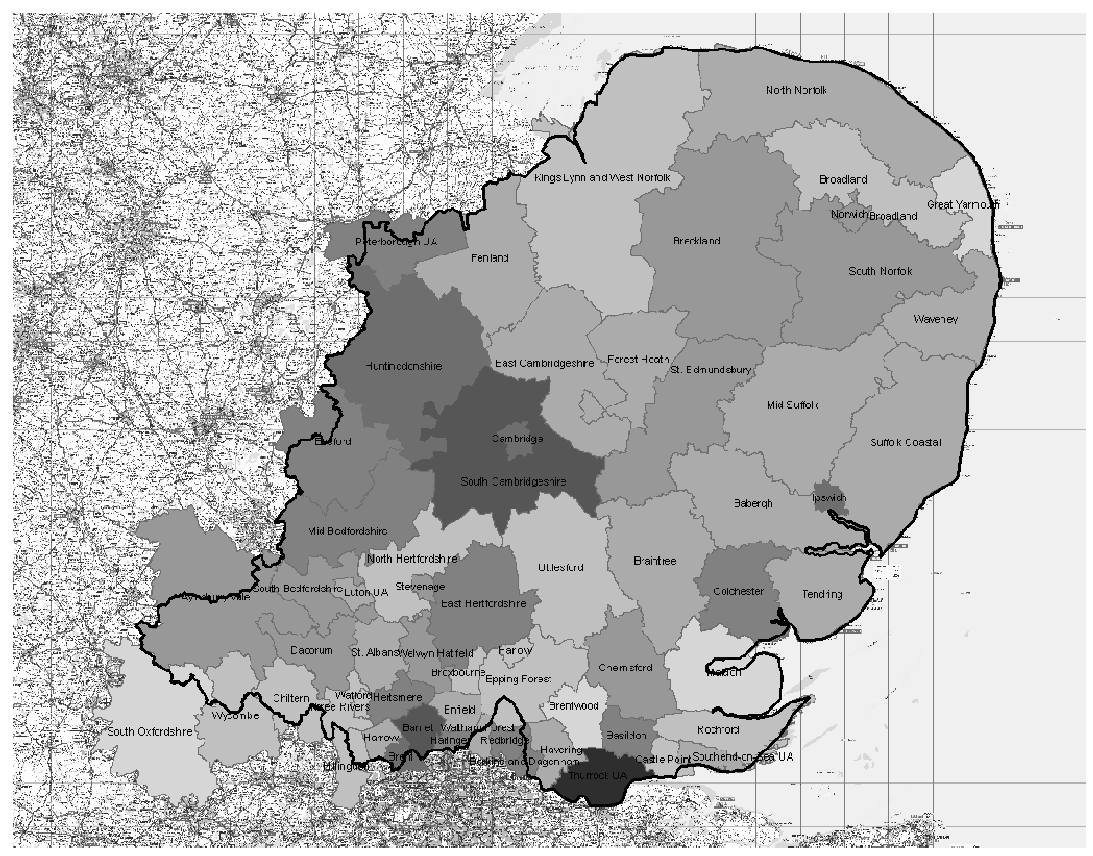

Year 2015

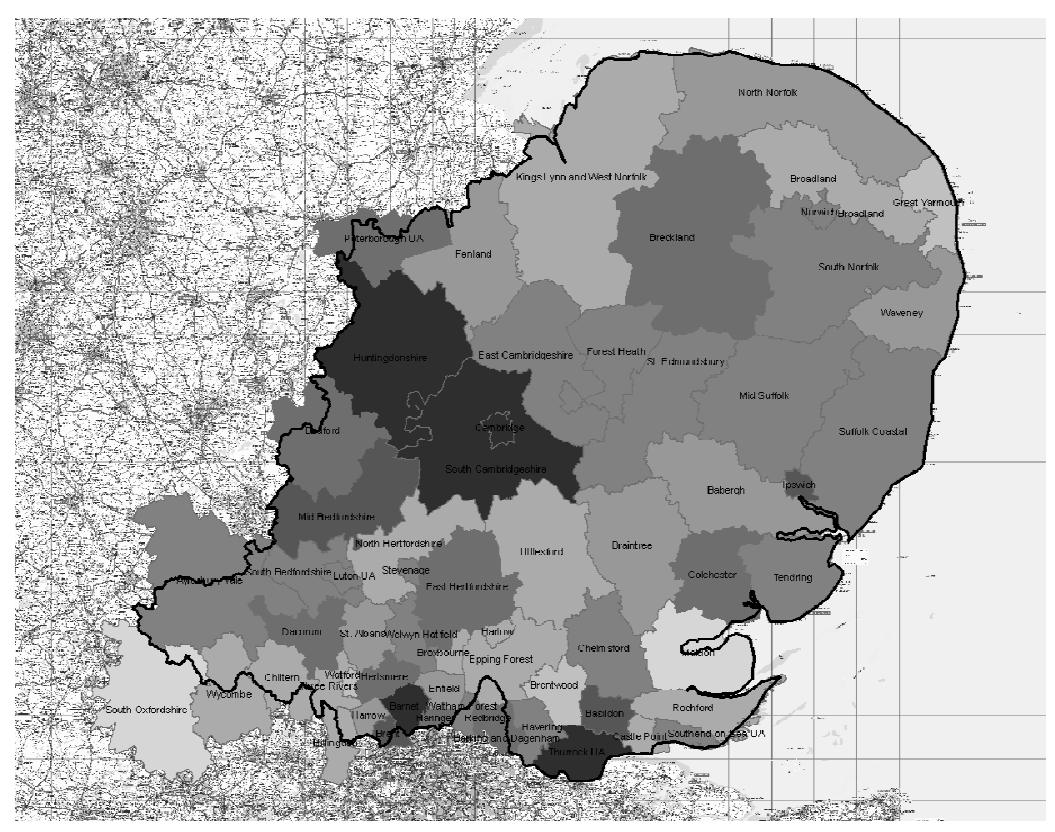

Year 2020

Figure 4: Regional demand growth in 2010, 2015, and 2020

Scale: $1: 1,500,000$ 


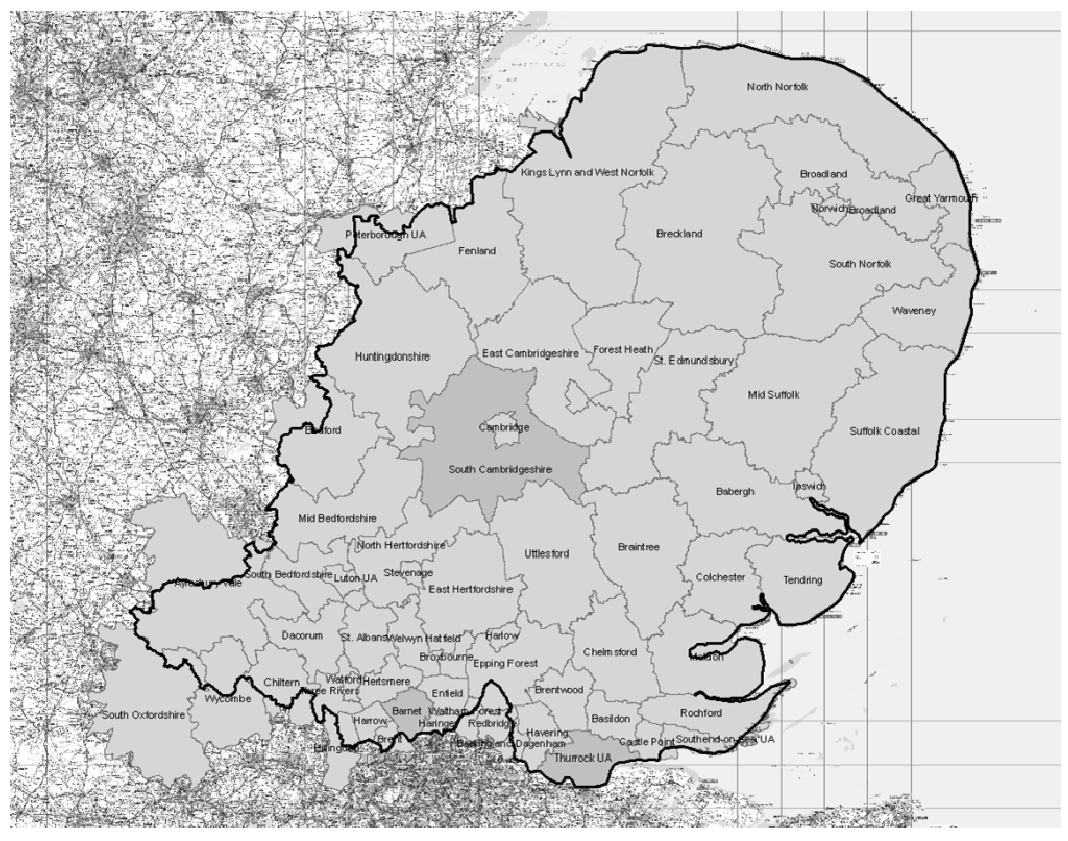

Year 2010

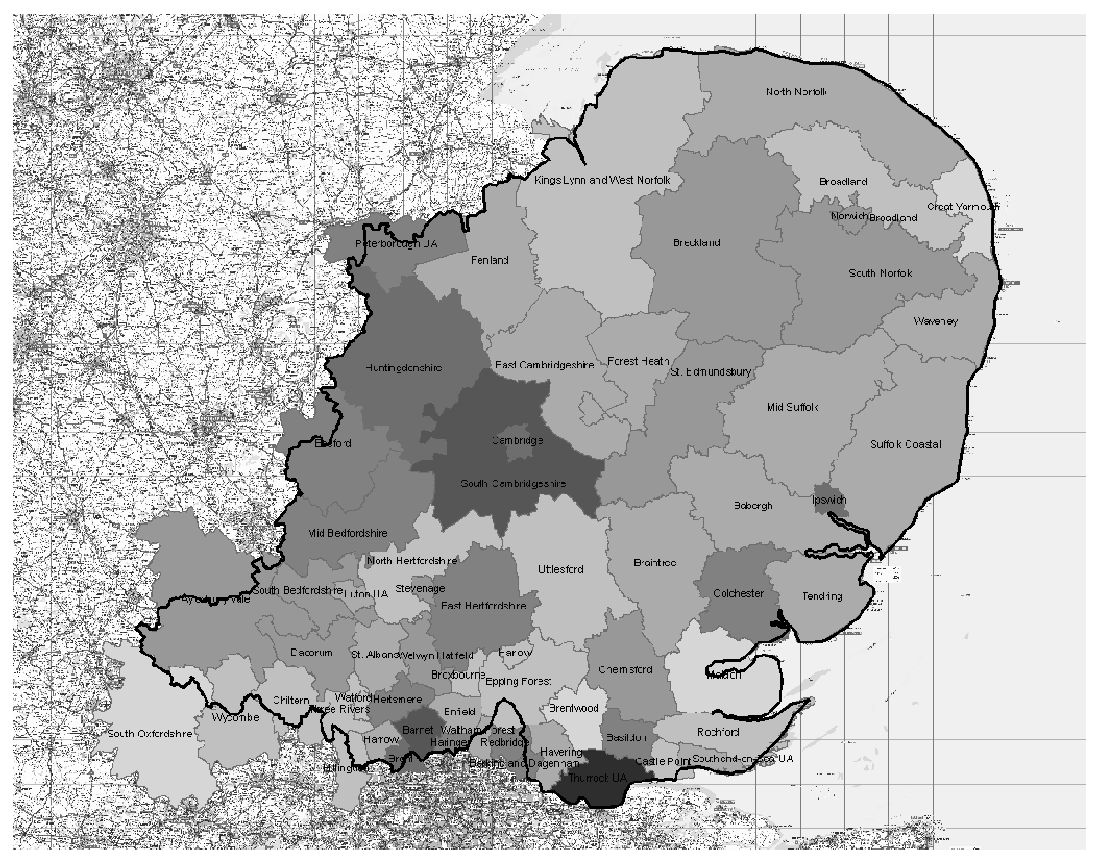

Year 2015 


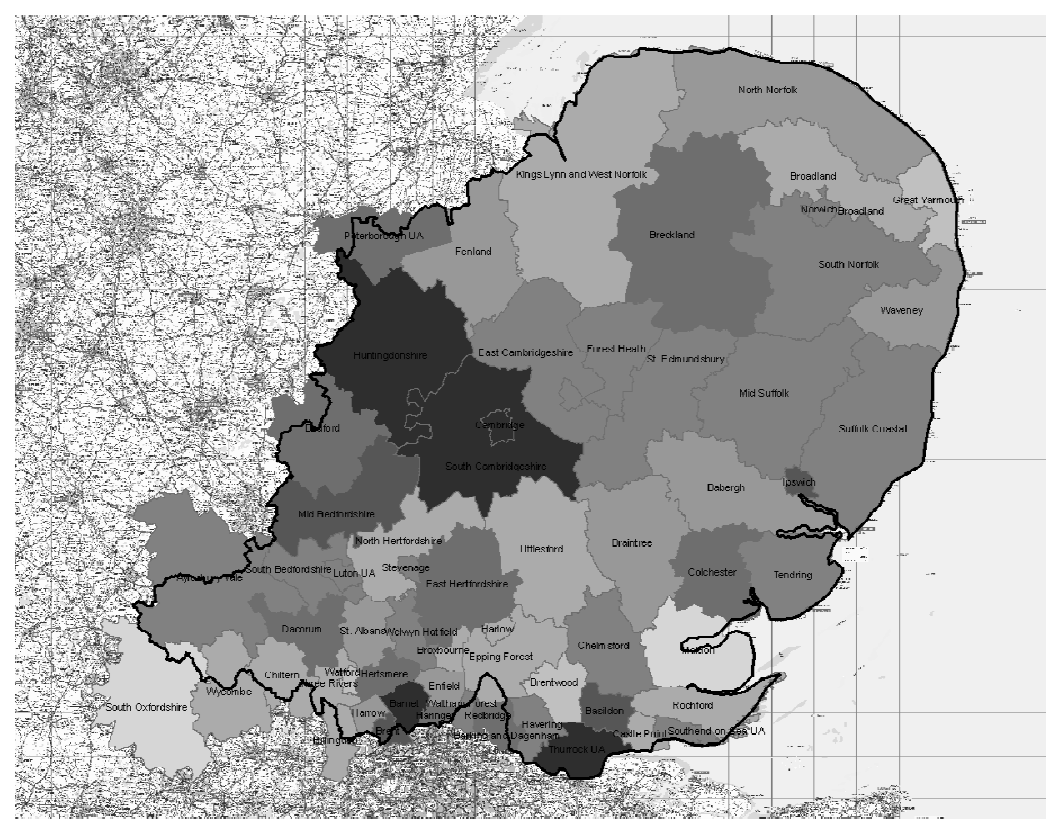

Year 2020

Figure 4 depicts the growth in maximum demand (MW)for all Local Authority Districts within EDF Energy Networks' EPN distribution network. Darker shades reflect higher demand growth. This provides a clear view of sections of the network where demand growth will be more significant in coming years, which in turn provides a high level indication of where demand related network investment might be required.

\subsection{Disaggregated electricity demand growth}

Regional demand growth forecasts are important as they provide a high level indication of the main electricity demand growth areas. However, as part of any network reinforcement assessment, knowing the existing demand on an electrical substation and consequently being able to estimate when its capacity will be insufficient to support predicted demand, is of paramount importance.

The next stage of the demand growth methodology here described is to calculate demand growth at a primary substation level (typically $33 / 11 \mathrm{kV}$ ), directly from the Local Authority District (regional) demand growth described above. This is achieved 
using the transformer rating and geographical location of the secondary substations (typically $11 / 0.4 \mathrm{kV}$ ), fed from each primary substation. Initially, the regional demand growth is spread across all secondary substations in a pro rata way. For example, this means that a 100kVA secondary substation will be allocated twice as much load as a 50 kVA. This demand is then aggregated back to a primary substation level, producing highly-disaggregated demand growth forecasts. This is an important step in the overall methodology as it allows for primary substations that supply neighbouring local authority districts which have different housing and employment targets. This has been possible through the use of GIS (Geographic Information System) tools, as they take into account the geographical location of district boundaries and primary and secondary substations.

Once demand growth forecast at a primary substation level is obtained, it is possible to identify those substations whose capacity would be insufficient to support predicted demand. Each primary substation is shown as an irregular shape cluster which represents the area it supplies. Here risk is defined as demand as a percentage of the primary substation capacity under $\mathrm{N}-1$ conditions (firm capacity). Because of confidentially reasons the firm capacity of the primary substations have been randomly generated and do not therefore represent their real firm capacity. Risk higher than $100 \%$ is shown in the darkest shade, greater than $85 \%$ in the middle shade and risk levels lower than $85 \%$ are shown in the lightest shade. 


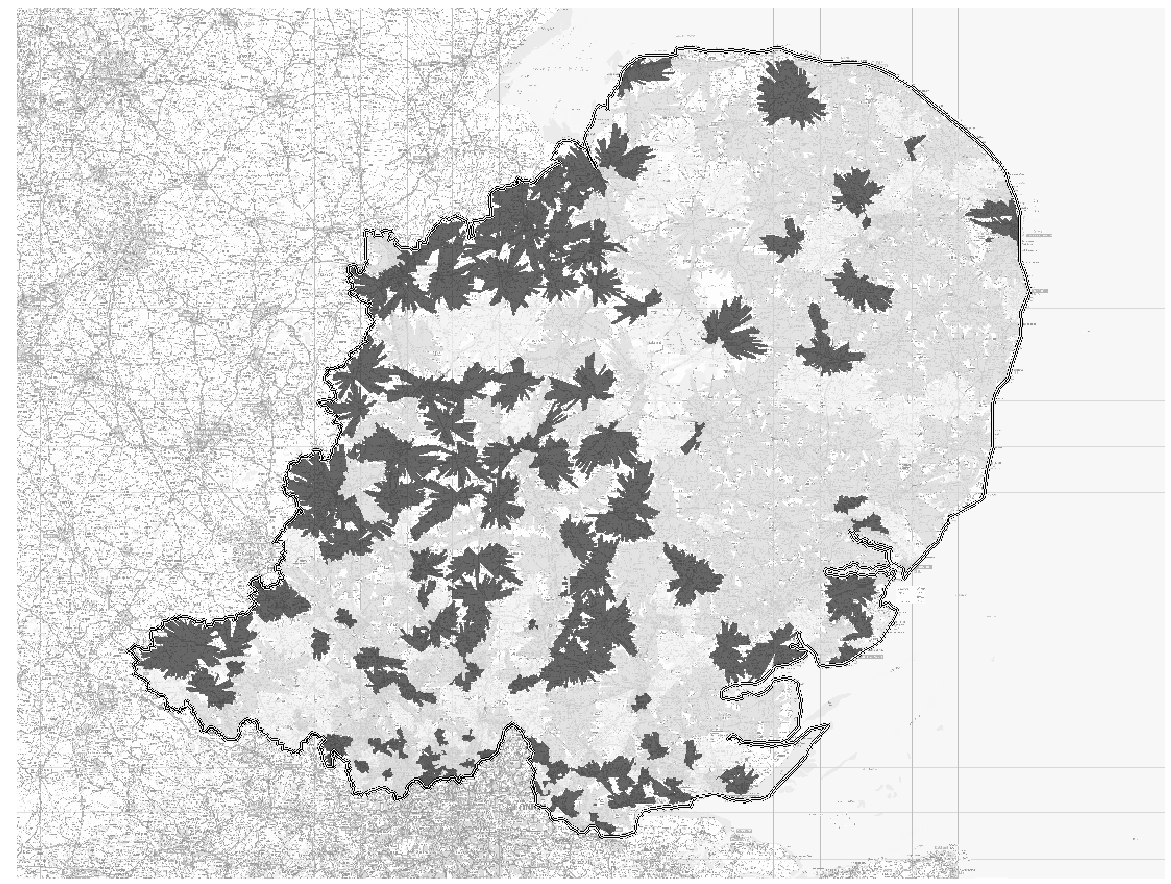

Year 2010

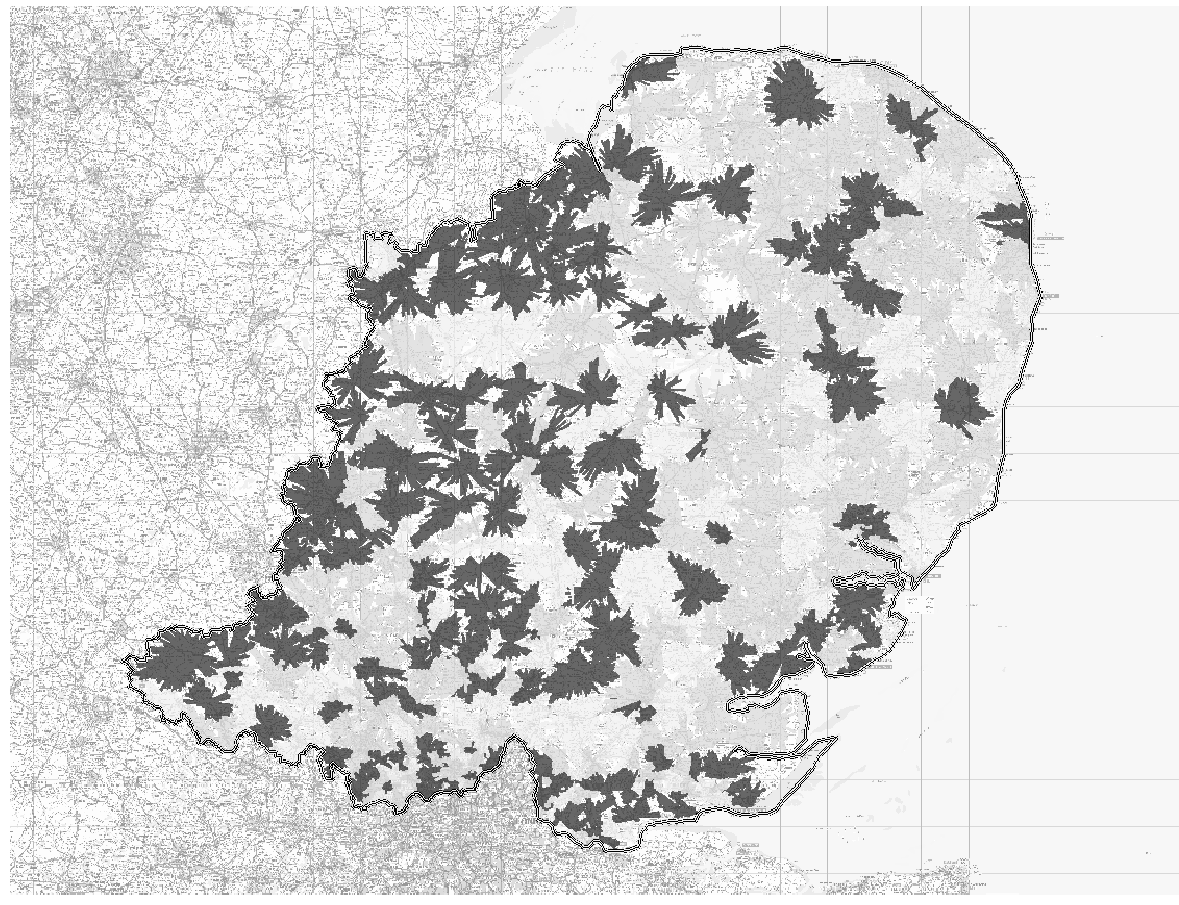

Year 2015 


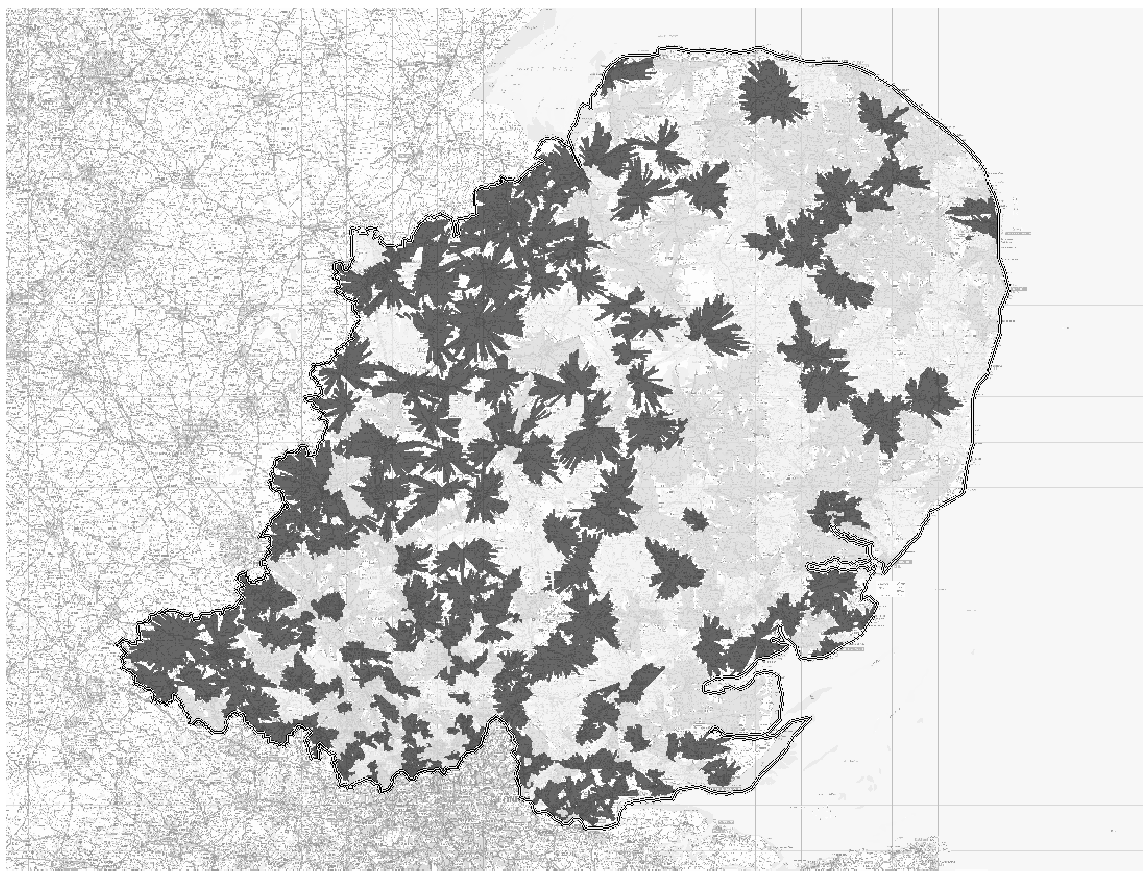

Year 2020

Figure depicts the level of risk that each primary substation within EDF Energy EPN distribution network would be subject to due to the regional demand growth portrayed in

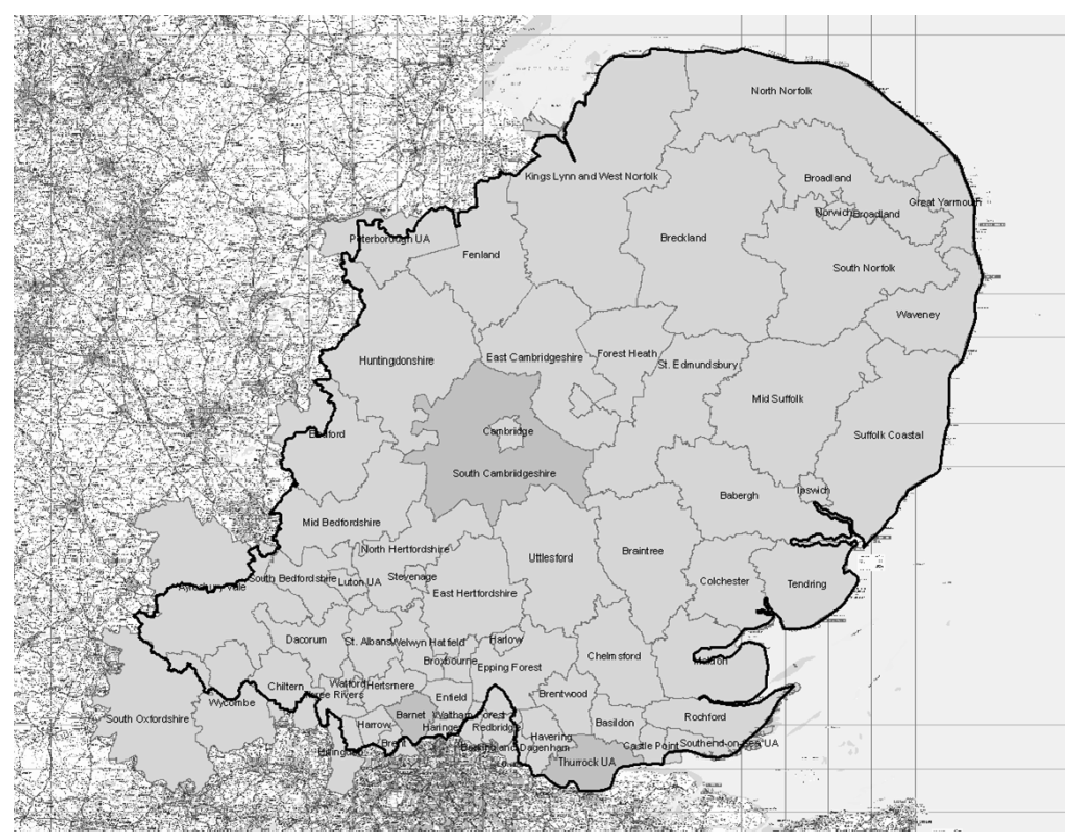

Year 2010 


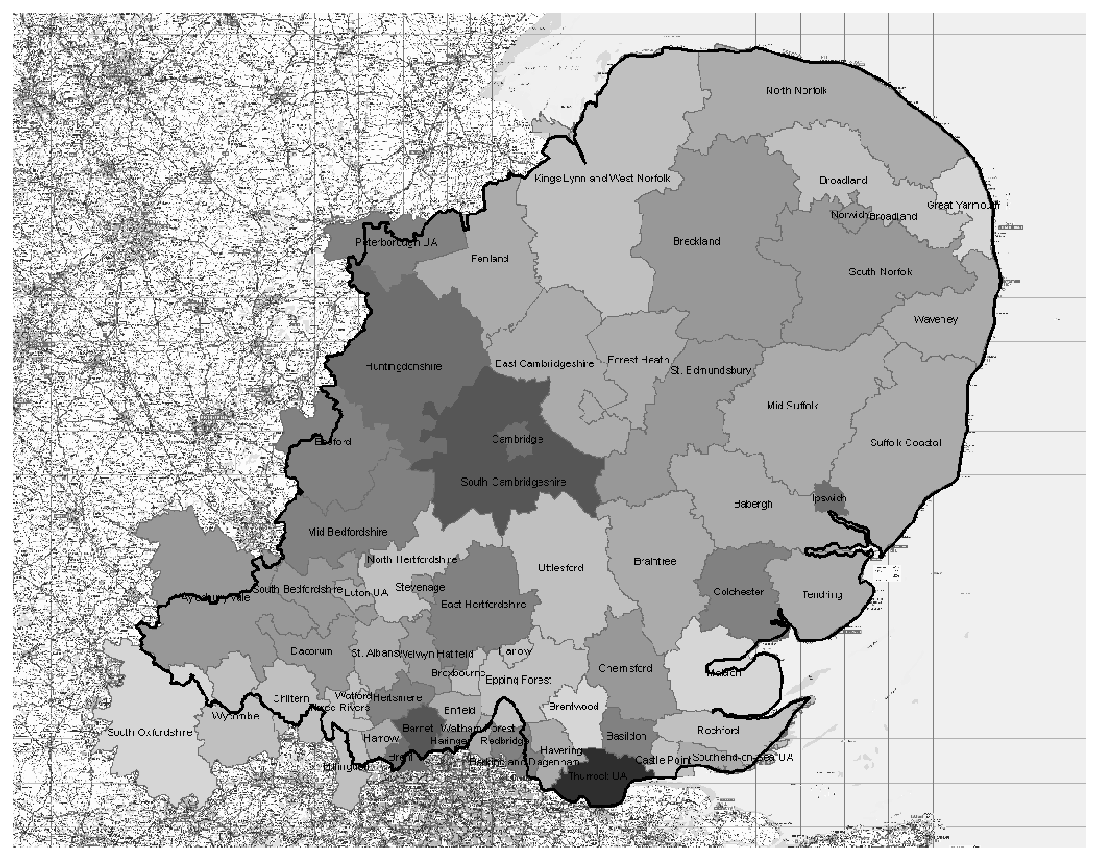

Year 2015

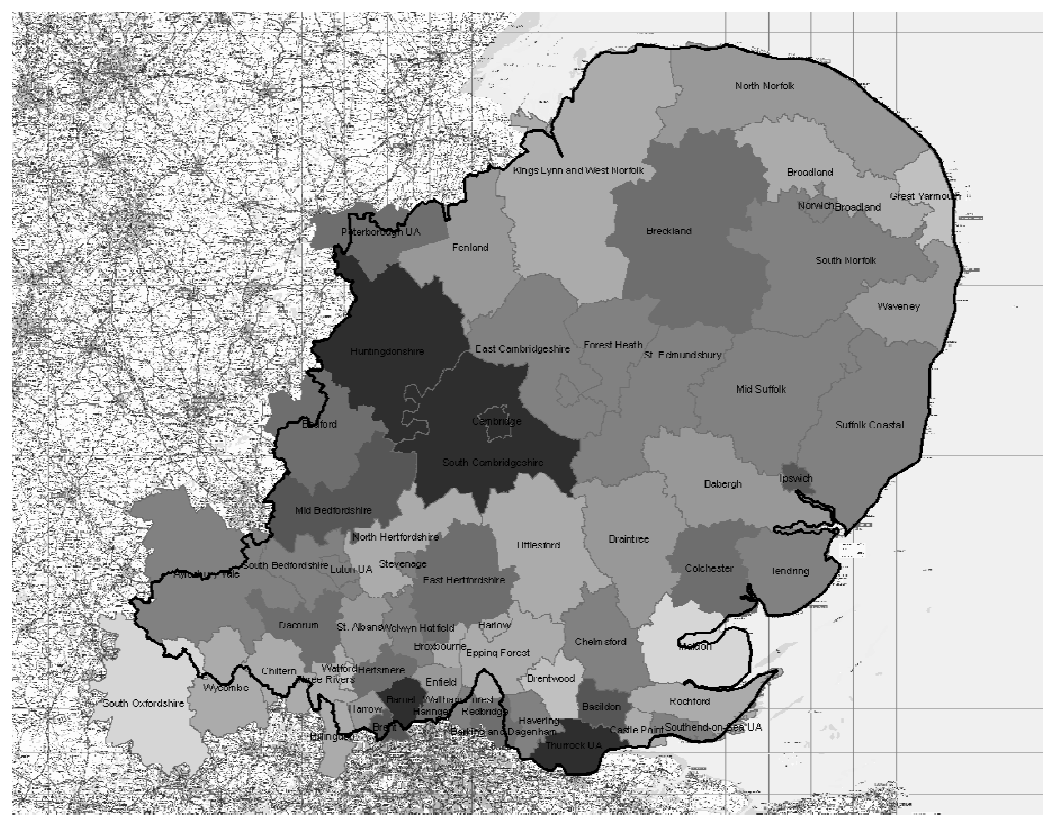

Year 2020

Figure 4 above.

Each primary substation is shown as an irregular shape cluster which represents the area it supplies. Here risk is defined as demand as a percentage of the primary 
substation capacity under $\mathrm{N}-1$ conditions $^{12}$ (firm capacity). Because of confidentially reasons the firm capacity of the primary substations have been randomly generated and do not therefore represent their real firm capacity. Risk higher than $100 \%$ is shown in the darkest shade, greater than $85 \%$ in the middle shade and risk levels lower than $85 \%$ are shown in the lightest shade.

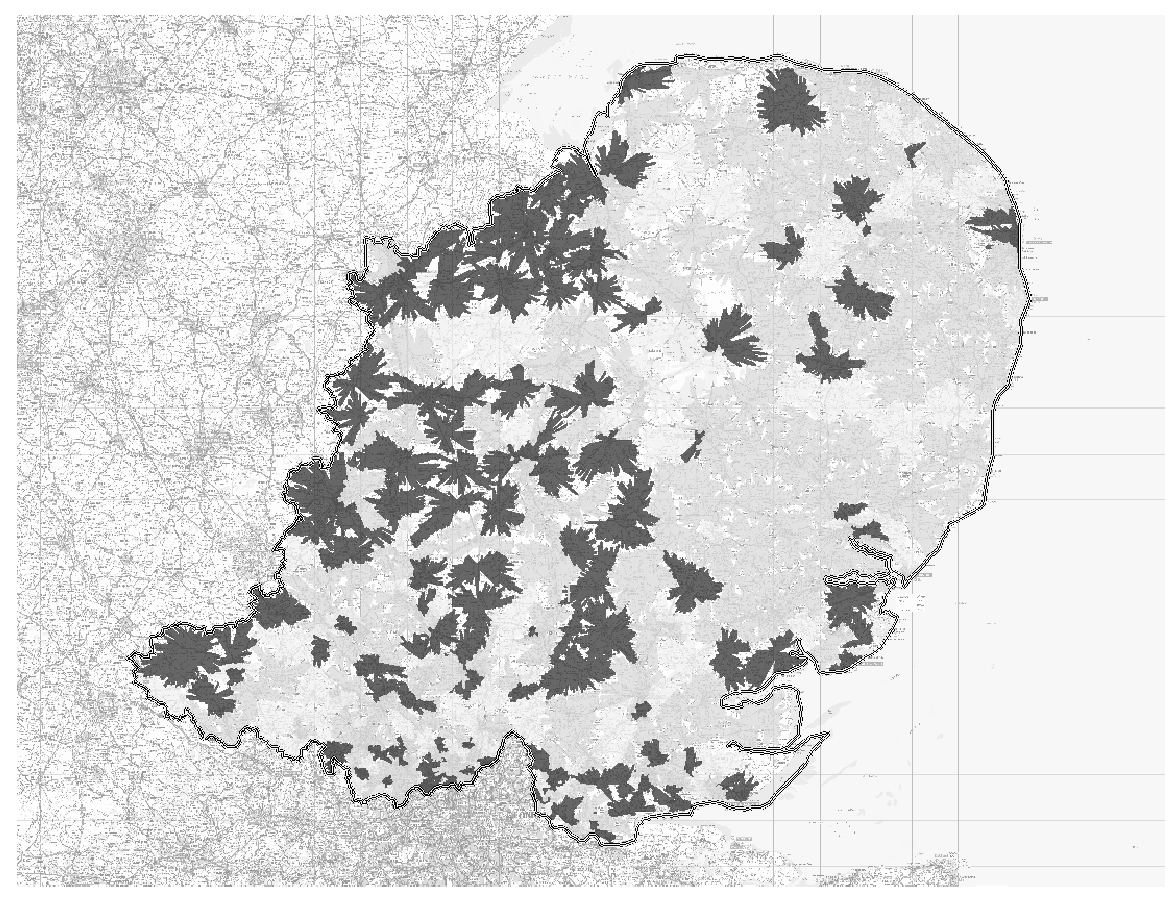

Year 2010

\footnotetext{
${ }^{12}$ Note that this is a simplification of $\mathrm{N}-1$ conditions set in ER P2/6.
} 


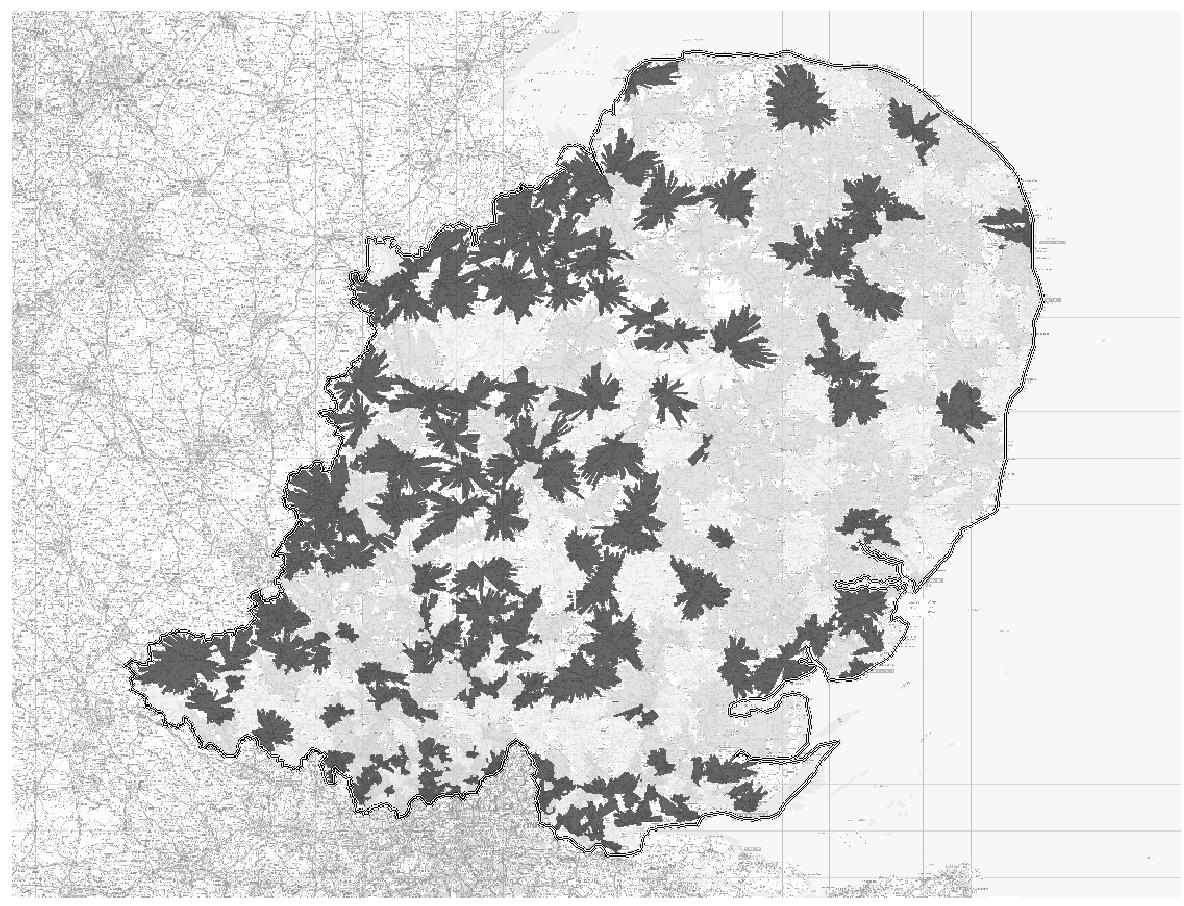

Year 2015

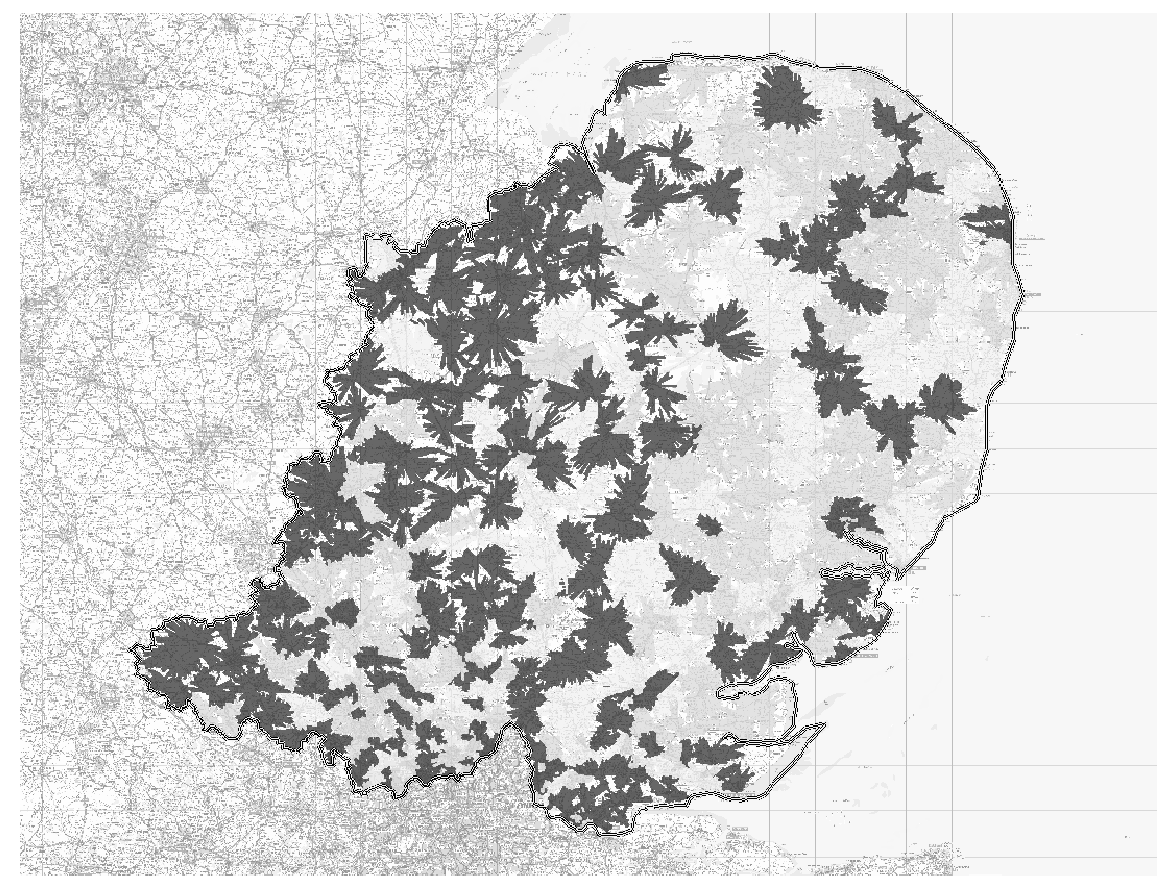

Year 2020

Figure 5 Primary substations risk level in 2010, 2015, and 2020

Scale: 1:1,500,000 
As shown in the above illustration, the model produces a clear picture of the primary substations that might need reinforcement, due to demand growth, in order maintain an acceptable level of risk. This risk level is set by the Engineering Recommendation P2/6. Moreover, the model outputs provide planning engineers with an analytical and visual aid to identify low risk primary substations adjacent to high risk ones. With this information, the possibility to transfer load from high risk primary substations to neighbouring low risk ones could be assessed. This could be a cost efficient way to support demand growth, defer reinforcements, and reduce the level of risk of capacity constrained substations.

\section{Relevance of the Model for Active Network and Demand and Concluding Remarks}

As demonstrated in the previous section, companies can use models (such as that of EDF described above) as sub-system network investment planning tools. The EDF model (for example) can use historical load development data and demand growth prognoses to determine emerging load-related investments in specific parts of the network at a detailed level. We also noted that network investments needs are capital intensive, most of the assets have long economic lives, and are often sunk costs upon investment.

The EDF model has practical applications for the evaluation of active network and demand options by coordination these with need of the network for upgrade and expansion in response to load growth. It can do so by feeding into other models and assessments of need for conventional investments at network and sub-network levels. In particular, the model can be used to assess the potential for the use of competing generic network and demand activating options in relation to the characteristics and expected future needs of specific parts of the network. 
Given the right regulatory incentives, such holistic approach to investments can increase the long-term economic and operational efficiency of the network. Such view of investment assessments will be fairly similar to the concept of Integrated Resource Planning (IPR) used by some public utility commissions in the US. Under IPR, regulated utilities are required to evaluate their generation capacity expansion plans not in isolation but also in relation to alternative supply sources such as other suppliers or demand-side options.

Similarly, the corresponding factors in the context of load capacity expansion in distribution networks in response to demand growth, these options include DG sources, combined heat and power (CHP) micro-generation technologies, active demand and smart meters, and various energy saving and efficiency alternatives.

At the same time, the level and nature of demand for electricity services is likely to change. For example, the expected emergence large scale adoption of electric vehicles (EVs) will add a fairly unknown but important to reckon with type of demand to the system. As discussed in Marsden and Hesse (this volume), the effect of large scale electric vehicles on total energy demand may not be very significant. However, their effect on system load could be considerable. A large scale adoption of EVs will require domestic as well as public charging facilities. In particular, provision of public charging facilities is likely to require fast charging and load-intensive facilities in order to encourage their use. The development of the infrastructure required for this will be costly and need careful assessment with regards to network planning. Similarly there may be significant effects as a result of the electrification of space heating via heat pumps (as discussed in Clarke et al., this volume).

A site-specific but integrated approach to network investment that includes the range of new supply and demand options will be clearly beneficial and can be aided by the type of modeling discussed here. However, achieving the full potential of the above options requires development of new suitable regulatory incentives. However a discussion of such appropriate regulation and incentive models is outside the scope of the present chapter. 


\section{References}

CEPA (2009). Ofgem: Research into Volume and Input Price Uncertainty for Electricity Distribution Price Control Review 5, Submitted to Ofgem by Cambridge Economic Policy Associates Ltd.

Frontier Economics (2007). The Association between unexpected changes in electricity volume and GDP growth for residential Customers, Report prepared for IPART, May.

Hyndman, R. J. (2007). Extended Models for Long-Term Peak Half-Hourly Electricity Demand for South Australia, Business and Economic Forecasting Unit, Monash University.

Jamasb, T. and Pollitt, M. (2007). Incentive Regulation of Electricity Distribution Networks: Lessons of Experience from Britain, Energy Policy, 35 (12): 6163-6187.

Jamasb and Pollitt (2008). Security of Supply and Regulation of Energy Networks, Energy Policy, 36: 4584-4589.

Joskow, P. (2008). Incentive Regulation and Its Application to Electricity Networks, Review of Network Economics, 7(4):547-560.

Mork, K.A. (1989). Oil and the Macroeconomy When Prices Go Up and Down: An Extension of Hamilton's Results. Journal of Political Economy, 97(3):740-744.

Niesten, E. (2010). Identifying Options for Regulating the Coordination of Network Investments with Investments in Distributed Electricity Generation, CPB Discussion Paper, No. 141.

Ofgem (2004), Electricity Distribution Price Control Review Final Proposals, Ref.265/04, London: Ofgem. 
Ofgem (2009), Electricity Distribution Price Control Review Final Proposals, Ref.144/09, London: Ofgem.

Ofgem (2010), Regulating energy networks for the future: RPI-X@20 Recommendations Consultation, Ref.91/10, London: Ofgem.

Pollitt, M. (2005). The Role of Efficiency Estimates in Regulatory Price Reviews: Ofgem's Approach to Benchmarking Electricity Networks, Utilities Policy, 13 (4): 279288.

Pollitt, M. and Bialek, J. (2008). Electricity Network Investment and Regulation for a Low Carbon Future. In: Grubb, M., Jamasb, T., and Pollitt, M. (Eds.), Delivering a LowCarbon Electricity System: Technologies, Economics, and Policy. Cambridge University Press, Cambridge, pp. 183-206.

Ofwat/Ofgem (2006). Financing Networks: A Discussion Paper, Office of Water Regulation/Office of Gas and Electricity Markets, Ofgem: London, UK.

Saplacan, R. (2008). Competition in Electricity Distribution, Utilities Policy, 16 (4): 231237. 